\title{
Reduction of strength of GFRP sandwich panels in naval ships by face sheet holes, cracks and impact damage
}

Hayman, Brian; Echtermeyer, Andreas T.

Published in:

Journal of Sandwich Structures and Materials

Link to article, DOI:

$10.1177 / 1099636219836357$

Publication date:

2019

Document Version

Peer reviewed version

Link back to DTU Orbit

Citation (APA):

Hayman, B., \& Echtermeyer, A. T. (2019). Reduction of strength of GFRP sandwich panels in naval ships by face sheet holes, cracks and impact damage. Journal of Sandwich Structures and Materials, 21(5), 1621-1653. https://doi.org/10.1177/1099636219836357

\section{General rights}

Copyright and moral rights for the publications made accessible in the public portal are retained by the authors and/or other copyright owners and it is a condition of accessing publications that users recognise and abide by the legal requirements associated with these rights.

- Users may download and print one copy of any publication from the public portal for the purpose of private study or research.

- You may not further distribute the material or use it for any profit-making activity or commercial gain

- You may freely distribute the URL identifying the publication in the public portal 


\title{
Reduction of Strength of GFRP Sandwich Panels in Naval Ships by Face Sheet Holes, Cracks and Impact Damage
}

\author{
Brian Hayman ${ }^{1}$ and Andreas T. Echtermeyer ${ }^{2}$
}

\section{Abstract}

Extensive studies have been previously carried out on the effects of various types of local damage on the performance of sandwich panels used in the hull structures of naval ships. More recently the approach was adapted for application on board a specific ship series. Strength reduction data were obtained for a set of sandwich materials that were representative for the vessels in question. The face sheet materials were glass fibre reinforced plastics (GFRP) with non-crimp fabrics and two different types of vinylester resin. The core materials were PVC foams. Tests were performed on laminate specimens with and without circular holes under tensile loading and on sandwich face sheets with holes, cracks and impact damage under compressive loading. The strength reductions caused by impacts with sharp and blunt objects were compared with those caused by machined cracks and circular holes, respectively, and with Whitney and Nuismer's point stress and average stress models for infinitely large laminates with cracks and holes. It was found that strength reductions due to impact damage can be estimated using tests on specimens with machined cracks and holes, and also with the average stress models if appropriate values of characteristic length are assumed. Special attention is paid to the need to take account of the geometry and the finite size of tested specimens.

\section{Key words}

Naval ships, Sandwich panels, Face sheet damage, Impact damage, Compression after impact, Damage assessment.

\section{Introduction}

Sandwich construction with face sheets of fibre-reinforced plastics (FRP) and a core of polymer foam or balsa wood has been used extensively in naval ships, especially in the Scandinavian countries. These developments have been to a large extent inspired by the pioneering efforts of a research team at the Royal Institute of Technology (KTH) in Stockholm, Sweden, of which the late Professor Karl-Axel Olsson was a key member until his retirement in 1998. Some of these naval applications, such as the Swedish Visby Class corvettes and the Norwegian Skjold Class fast attack craft, involve the use of highly optimised sandwich solutions.

\footnotetext{
${ }^{1}$ Department of Mechanical Engineering, Technical University of Denmark, Kongens Lyngby, Denmark.

${ }^{2}$ Department of Mechanical and Industrial Engineering, NTNU - Norwegian University of Science and Technology, Trondheim, Norway.
}

Corresponding author:

Brian Hayman, Ullern allé 69, Oslo NO-0381, Norway. Email: Brianhayman.no@gmail.com 
In the period 2001-2005, extensive studies were carried out in a collaboration between the Norwegian, Swedish, Danish, Finnish and British navies, research institutions, shipyards and other suppliers of materials and services on the effects of various types of in-service damage and production defects on the structural performance of sandwich panels used in the hull structures of naval ships [1-3]. The project was led by the current paper's first author, and major contributions were made by some of Professor Olsson's successors at KTH [2]. These studies included the development of a damage assessment scheme that takes into account the effects on global hull strength as well as local panel strength. Specific data were obtained for the residual strength of a selection of sandwich materials in the presence of face-core and core-core debonds, face sheet wrinkles, core shear fracture and several types of impact damage. Subsequently the approach was adapted for use in connection with a specific Royal Norwegian Navy ship series. This involved the establishment of strength reduction data for a set of sandwich material layups that were representative for the vessels in question. The selected layups had glass fibre reinforced plastic (GFRP) face sheets and PVC foam cores.

It should be emphasised that these studies were concerned with scenarios in which defects and damage are observed and their nature, size and extent can be, at least to some extent, determined by some form of inspection. The main concern is to evaluate their consequences for the subsequent safety and performance of the vessel and its systems. As pointed out by Sutherland [4,5], this approach conveniently avoids to a large extent the need to establish the precise nature of the events and mechanisms that have initially led to the defects or damage.

The current paper focuses on the studies performed on sandwich panels with local face sheet impact damage under in-plane tensile and compressive loadings. It presents new test results and correlation with available damage models. The specific objectives are as follows:

- To investigate the applicability of models in which damage due to a blunt impacting object is replaced by a circular hole in the face sheet, and that due to a sharp impacting object is replaced by a crack that penetrates the face sheet.

- To generate curves of strength reduction plotted against the size of the damage.

- To provide guidance on how to generate such curves for other sandwich layups and materials.

Some results have been presented previously at international conferences [6,7], but the present paper provides a more complete presentation and evaluation of the work. An associated study of the performance of similar sandwich panels under in-plane compressive loading in the presence of face-core debonds has been reported earlier by Moslemian et al. [8].

\section{Impact damage models}

Impacts on a lightweight FRP sandwich structure may cause damage to the face sheet and also to the underlying core. In some impact events on panels with ductile cores, the core becomes permanently indented and the face sheet remains attached to it, also retaining a 
permanent dent. In other impact events, especially with less ductile cores, the damaged face sheet becomes detached from the core in the region of damage. The damage may be in the form of a dent, a hole or a crack, or a region with distributed cracks and delaminations.

In the earlier work [2], three alternative models were used to represent these scenarios:

- A hole model, in which a circular area corresponding approximately to the damage area, is considered to be removed from the face sheet and the reduction in the face sheet strength is assessed without reference to the supporting core material. This is appropriate to many cases of impact with a blunt object having dimensions much less than those of the panel.

- A crack model, similar to the hole model, in which the hole in the face sheet is replaced by a single, through-thickness crack. This is appropriate to many cases of impact with a sharp object, such damage being generally visible to the naked eye.

- A dent model, in which the face sheet is considered to be dented while remaining attached to the underlying core, which may be partially crushed.

The studies with the hole and crack models were confined to cases with faces reinforced by carbon fibres. The modelling approach used in both cases was similar to that reported by Soutis et al. [9-11] and performed using the Composite modeller software developed by Sutcliffe et al. [12]. Only loading with in-plane compression after impact was considered. In addition to panels with machined holes and cracks, tests were performed on panels with real sharp and blunt impacts, enabling guidelines to be developed for selecting an equivalent hole or crack size to use when applying the hole and crack models.

In the studies reported here, the results were extended to cover the strength of GFRP face sheets with circular holes, cracks and real impact damage caused by both blunt and sharp objects, including some cases with tensile loading.

\section{Whitney and Nuismer point stress and average stress criteria}

For tensile loading of laminates with circular holes, the Whitney and Nuismer point stress and average stress criteria [13] are available, though the characteristic lengths for use in these criteria need to be established experimentally for the materials and layups in use here. This approach does not consider the detailed local failure mechanisms involved, but assumes that tensile failure of the laminate occurs when the tensile stress in the direction of loading reaches a critical value that is the same for a specimen with a hole as for a specimen without one, so that the failure mechanism in itself is not affected by the presence of the hole or crack. As a fibre-reinforced laminate has an inhomogeneous internal structure with physical gaps between the reinforcement fibres, when a hole is present the stress is not simply evaluated at the edge of the hole. In the point stress approach it is instead evaluated at a point a short distance $d_{0}$ away from the hole, while in the average stress approach the stress is averaged over a short distance $a_{0}$ from the hole edge. The characteristic distance $d_{0}$ or $a_{0}$ is assumed to be a property of the laminate 
material and layup. It is found by performing tensile tests on face sheet laminate specimens with holes of various diameters and finding the $d_{0}$ or $a_{0}$ value that gives the best fit, as summarised below. A similar procedure is used for cracks or slits in the direction transverse to the loading direction.

For compressive loading Nuismer and Labor [14] later found that similar procedures could be used, though these gave larger values of the characteristic lengths. It should be noted that, for compression, there are more potential local failure mechanisms including fibre buckling and delamination, so the assumption that the failure mechanism remains unaltered by the presence of the hole or crack is more questionable.

The Whitney and Nuismer approach is adopted here because it is based on relatively simple, closed form solutions that can readily be used in parametric studies to generate design curves, with a limited amount of laboratory testing to establish the most appropriate values of the characteristic length $d_{0}$ or $a_{0}$. In the four decades since the approach was originally developed, considerably more knowledge has been accumulated concerning both the damage mechanisms involved and their influence on the residual strength of composite structures. In parallel with the introduction of improved failure criteria for laminates [15-17], developments in analysis techniques have made possible more scientific approaches to the modelling of progressive damage and failure estimation [18-20]. However, these remain complex and time-consuming in their use. The goal with the present work is to provide data that can be used in practice when time and resources may not be readily available for detailed analysis.

\section{Circular holes}

Figure 1(a) shows a circular hole of radius $R$ in an isotropic laminate, considered to be of infinite extent, with the origin of an $x-y$ axis system at the centre of the hole. If a uniform tensile stress $\sigma_{a}$ is applied parallel to the $y$-axis at infinity, then the variation of the normal stress $\sigma_{y}$ along the $x$-axis is given by

$$
\frac{\sigma_{y}}{\sigma_{a}}=1+\frac{1}{2}\left(\frac{R}{x}\right)^{2}+\frac{3}{2}\left(\frac{R}{x}\right)^{4}
$$

where $x$ is the distance from the centre of the hole. From this relation Whitney and Nuismer [13] derived the point stress criterion, which specifies the applied mean stress $\sigma_{N}$ at which the stress at a distance from the hole equal to a characteristic length $d_{0}$ reaches the failure strength $\sigma_{0}$ for the unnotched material:

$$
\frac{\sigma_{N}}{\sigma_{0}}=\frac{2}{2+\xi_{1}^{2}+3 \xi_{1}^{4}} \quad \text { where } \quad \xi_{1}=\frac{R}{R+d_{0}}
$$

They derived similarly the average stress criterion, which specifies the applied mean stress $\sigma_{N}$ at which the average stress up to a distance from the hole equal to a characteristic length $a_{0}$ reaches the failure strength $\sigma_{0}$ for the unnotched material:

$$
\frac{\sigma_{N}}{\sigma_{0}}=\frac{2\left(1-\xi_{2}\right)}{2-\xi_{2}^{2}-\xi_{2}^{4}}=\frac{2}{(1+\xi)\left(2+\xi^{2}\right)} \quad \text { where } \quad \xi_{2}=\frac{R}{R+a_{0}}
$$


The two equations give somewhat different relationships between the size of the hole and the strength reduction. Based on tests on glass-epoxy laminates, Whitney and Nuismer found that the average stress criterion gave a better fit to experimental data than did the point stress criterion. Note that for very small holes $(R \rightarrow 0)$ equation (3) gives $\sigma_{N} / \sigma_{0} \rightarrow 1$, i.e. no strength reduction, while for large holes, or very small characteristic lengths, with $R>>a_{0}, \sigma_{N} / \sigma_{0} \rightarrow 1 / 3$, corresponding to the classical stress concentration factor 3 .

The aim of the current studies is to determine values of the local strength reduction factor $R_{l}$, defined as the ratio of the compressive strength of a damaged panel to that of the corresponding intact panel, which is a convenient parameter for use in damage assessment procedures [1-3]. In terms of the Whitney and Nuismer models, this is the same as the quantity $\sigma_{N} / \sigma_{0}$.

The above relationships apply for a plate of infinite extent, or for a case where the hole diameter is very much smaller than the plate size. However, a measured strength (and deduced strength reduction) depends not only on the size of the damage but also on the geometry and size of the test specimen. It is extremely important that results of tests on plate specimens of finite dimensions, such as those tested in the current study, are appropriately adjusted if they are to be compared with theories for plates of infinite width, or if they are to be applied in situations where the hole diameter is very much smaller than the plate width.

\section{Finite width adjustment for circular holes}

Whitney and Nuismer's tests [13] were performed on 2-inch $(50.8 \mathrm{~mm})$ wide strips of laminated composite with central holes; the laminates with circular holes tested under tension in the current study had similar dimensions. The test results were expressed in terms of the applied stress obtained by dividing the applied load by the gross crosssectional area, rather than the net cross-sectional area (in which the part of the cross section removed by the hole is deducted); these results were then adjusted to allow for the finite width of the tested specimen. Thus the measured failure loads were converted to what they would have been if the plates had been infinitely wide, before the test results were compared with predictions based on the point stress and average stress criteria. The correction was performed in accordance with a procedure given in Peterson [21], based on a paper by Howland [22]. Peterson also gives an approximation to the required correction factor due to Heywood [23]:

$$
\frac{k_{t g}}{k_{t g \infty}}=\frac{2+(1-a / w)^{3}}{3(1-a / w)}
$$

where $k_{t g}$ is the stress concentration factor, based on the gross cross-sectional area, for a plate of finite width $w, k_{\text {tgo }}$ is that for an infinitely wide plate, and $a$ is the hole diameter $(=2 R)$. The Heywood approximation is quite accurate, but with increasing error as the ratio $a / w$ increases. The error at $a / w=0.5$ is stated as being $1.5 \%$. In fact a slightly better fit to the Howland curve is given by 


$$
\frac{k_{t g}}{k_{t g \infty}}=\frac{2+(1-a / w)^{3.1}}{3(1-a / w)^{1.03}}
$$

Note that the factor defined in equations (4) and (5) is that by which the maximum stress induced by a given applied uniaxial stress in an infinite plate must be multiplied to give the maximum stress induced by the same stress applied to a plate of finite width. It includes the effect of the reduced cross-sectional area due to the hole, together with the change in distribution of stress across the portion of plate between the hole and the edge of the plate. These two effects work in opposite directions, the loss of cross-sectional area being the greater so that the factor is always greater than unity. Thus the factor is that by which a notched strength measured using a finite width specimen should be multiplied to obtain the notched strength that would have been measured if an extremely large specimen had been used. Conversely, it is the factor by which the theoretical notched strength based on an infinitely large plate should be divided to estimate the notched strength of a similar plate of finite width.

The Peterson/Heywood correction is based on the dependence of the stress concentration at the edge of the hole on the specimen width, relative to the hole size. This is not strictly correct if the point stress or average stress criterion is being applied as these criteria refer to stresses not at the hole edge but some distance away from it. In the present work, for those tests performed on long strip specimens, a more refined correction is applied that considers the change in stress concentration at the point at which the point stress criterion is applied, or the change in the average stress over the characteristic length if the average stress criterion is being applied. In the present study, the corrections have been derived on the basis of Howland's original analysis [22]. Howland provided a series solution that gave the following expression for $\sigma_{y}$ at points along the cross-section $y=0$ :

$$
\begin{aligned}
& \left.\frac{\sigma_{y}}{\sigma_{a}}\right|_{f w}=\frac{\sigma_{\theta}}{\sigma_{a}}=1+2 m_{0}+\frac{c_{0}}{\rho^{2}}+ \\
& +2 \sum_{n=1}^{\infty}\left[\frac{n(2 n+1)}{\rho^{2 n+2}} c_{2 n}+\frac{(n-1)(2 n-1)}{\rho^{2 n}} e_{2 n}+n(2 n-1) \ell_{2 n} \rho^{2 n-2}+(n+1)(2 n+1) m_{2 n} \rho^{2 n}\right]
\end{aligned}
$$

where the suffix $f w$ refers to the finite width case,

$$
\lambda=2 R / w=a / w
$$

and

$$
\rho=2 x / w
$$

Numerical values of the dimensionless coefficients $m_{0}, m_{2}, \ldots, c_{0}, c_{2}, \ldots, e_{2}, e_{4}, \ldots$, and $\ell_{2}$, $\ell_{4}, \ldots$ were given in a table for $\lambda=0.1,0.2,0.3,0.4$ and 0.5 . It is found that only the first few terms in the series give significant contributions for cases relevant to the present study. The finite width correction factor for the point stress criterion is found by setting $x$ $=d_{0}$ in equation (6) and dividing by the expression in equation (2). To obtain the correction factor for use with the average stress criterion requires integration of equation (6) over the region $x=R$ to $x=R+a_{0}$, i.e. $\rho=\lambda$ to $\rho=\lambda+a_{0} / w$ and dividing by the 
expression in equation (3). An excellent fit for the derived correction factor is given by modifying equation (5) to give

with

$$
\frac{k_{t g}}{k_{\text {tg } \infty}}=\frac{2+(1-a / w)^{3.1}}{3(1-a / w)^{1.03}}\left(1-k \lambda^{2.5}\right)
$$

$$
k=2.37 \alpha(1-\alpha), \quad \alpha=2 a_{0} / w
$$

If the characteristic length $d_{0}$ or $a_{0}$ is known, the test results for a laminate specimen of finite width can be adjusted by this factor to give the results that would have applied if the specimen had been infinitely wide, i.e. if the damage had been very much smaller than the plate width. When experimental data are first being analysed, the characteristic length is not known, but is to be determined by finding which characteristic length gives the curve that best fits the data. Then it is best first to adjust the theoretical Whitney and Nuismer curves for a series of values of characteristic length so they apply to the specimen width used in the tests, and then find the characteristic length that gives the best fit to the uncorrected test data. Once the characteristic length has been determined in this way, the results can all be transformed back to the infinite width condition.

The above correction is based on the assumption that the test specimen consists of a long strip of isotropic material subjected to tension. In principle it should also apply to similar strips tested in compression, provided it is assumed that the failure mechanisms will be the same for the strip with and without the hole. However, buckling of the test specimen prevents the use of laminate strips for this purpose. In the present study, compression tests were performed on the face sheets of square sandwich specimens with penetrating circular holes, so that the presence of the core inhibits buckling. For such specimens the finite width correction described above is not strictly valid. For square specimens, a correction factor can be derived from numerical studies of square, isotropic plates with central holes under in-plane, uniaxial tension or compression such as that by Hong and Crews [24]. This showed a significant difference in stress states close to the hole according to whether the compressive loading on opposite edges was applied as a uniform stress or a uniform displacement. In the tests described below, the loading was applied through very stiff, steel beams, so that the uniform displacement case appears the more appropriate. Hong and Crews tabulate, for a series of values of $a / w$, values of the stress concentration factor at the edge of the hole, referred to the net cross-sectional area at the transverse section through the centre of the hole. The stress concentration factor based on the gross section is obtained by dividing this by $(1-a / w)$. It is not possible to deduce from the presented results the stresses at other points in the cross-section, so the correction is here based on the stress at the edge of the hole, which would correspond to a stress concentration factor of 3 for an infinitely large plate (or infinitely small hole). Furthermore, Hong and Crews tabulate numerical results only for a limited number of $a / w$ values. In the present study it was found that the correction factor can be approximated by the formula: 


$$
\frac{k_{t g}}{k_{\operatorname{tg} \infty}}=\frac{3-3.1(a / w)+2(a / w)^{2}+0.7(a / w)^{3}-0.55(a / w)^{4}}{3(1-a / w)}
$$

For $a / w \leq 0.5$, this approximation deviates less than $1 \%$ from the tabulated results of Hong and Crews. This correction has been applied in deriving the results for square specimens shown later. In a preliminary analysis the strip-based correction was applied; Figure 2 compares the finite width correction factors for long strips and square plates with central holes obtained by the different methods. The curves for the long strip cases refer to characteristic lengths $a_{0}$ in the range of interest. It is seen that the correction applied by the square plate case is somewhat smaller than for the long strip cases, and significantly smaller than that for the long strip with $a_{0} / w=0$.

Cracks perpendicular to the load direction

Whitney and Nuismer [13] also considered the case of an infinite plate with a narrow, elliptical crack of length $2 \mathrm{c}$ and a uniform tensile stress applied in the $y$-direction (Figure $1 b)$. They showed that the value of the stress $\sigma_{y}$ at $(x, 0)$ is given by

$$
\sigma_{y}=\frac{K_{I} x}{\sqrt{\pi c\left(x^{2}-c^{2}\right)}}
$$

where $K_{I}$ is the mode I stress intensity factor given by

$$
K_{I}=\sigma_{a} \sqrt{\pi c}
$$

Assuming the average stress criterion applies, failure is expected to occur when the average stress between $x=c$ and $x=c+a_{0}$ reaches the unnotched strength $\sigma_{0}$. Then

$$
\sigma_{0}=\frac{1}{a_{0}} \int_{c}^{c+a_{0}} \sigma_{y}(x, 0) d x=\sigma_{a} \sqrt{\frac{2 c+a_{0}}{a_{0}}}
$$

This gives the value of $\sigma_{a}$ at failure, $\sigma_{N}$, and thus the local strength reduction factor $R_{l}$ due to the crack:

$$
R_{l}=\frac{\sigma_{N}}{\sigma_{0}}=\sqrt{\frac{a_{0}}{2 c+a_{0}}}
$$

Whitney and Nuismer compared failure loads predicted by both criteria to results for graphite/epoxy laminates with layup $(0 / \pm 45)_{S}$ found from tests on parallel-sided strip specimens with central, transverse cracks by Konish and Cruse [25]. They concluded that the values of the characteristic lengths $d_{0}$ and $a_{0}$ were the same for the cracks in these triaxial graphite/epoxy laminates as for the holes in the quadriaxial, quasi-isotropic glass/epoxy laminates they themselves had tested, and postulated that they were thus universal values for FRP laminates. However, this conclusion is based on a very limited range of materials and layups, and it is perhaps more likely that the characteristic lengths are functions of the coarseness of the reinforcement fabric architecture, and possibly also of the component materials. In the present study only cases with in-plane compression loading on the face sheets of square sandwich specimens are considered.

\section{Finite width adjustment for cracks}

The tests on strip specimens with central cracks reported by Konish and Cruse [25] all had the same $2 c / w$ ratio of 0.4 . It is unclear whether any form of finite width correction was applied when the results were compared with the Witney and Nuismer failure 
criteria. In the present work, when the results of tests on specimens with cracks are processed, a correction for the finite width of the specimen is applied, as was done for specimens with circular holes. In the absence of data for square plates, the formula for long strip specimens attributed to Koiter [26] is used:

$$
\frac{k_{t g}}{k_{t g \infty}}=\frac{1-0.1 \frac{2 c}{w}+0.326\left(\frac{2 c}{w}\right)^{2}}{\sqrt{\left(1-\frac{2 c}{w}\right)}}
$$

This gives values of the correction factor that agree very closely with a formula proposed by Brown and Srawley [27] based on results from three earlier studies.

\section{Materials, specimens and material properties}

The materials and layups selected for the present study are representative for hulls and superstructures of vessels operated by the Royal Norwegian Navy, though the layups and dimensions have been scaled for convenience in testing. The face sheet materials are glass fibre reinforced plastics (GFRP) with Devold AMT non-crimp fabrics and two different types of vinylester resin. In order to limit the number of tests, only quasiisotropic face sheet layups have been included in the study. The core materials are two Divinycell closed-cell PVC foams.

The specimen types and layups are listed in Table 1, together with the types of tests to which they were subjected, details of which are provided in the respective sections below. For tensile testing, $300 \mathrm{~mm}$ x $50 \mathrm{~mm}$ parallel-sided laminate strip specimens without core were used, but for compressive testing the specimens were 150 $\mathrm{mm} \times 150 \mathrm{~mm}$ square sandwich panels, and also some $300 \mathrm{~mm} \times 300 \mathrm{~mm}$ panels. The face sheet materials were as follows:

- Type A: DBLT-850 quadriaxial (0/90/+45/-45) glass with Dion 9102 vinylester.

- Type B: As type A but with Dion 9500 rubber-modified vinylester.

Each layer of DBLT-850 fabric contained approximately $835 \mathrm{~g} / \mathrm{m}^{2}$ of glass reinforcement. In the sandwich specimens each face had in addition a $100 \mathrm{~g} / \mathrm{m}^{2}$ layer of chopped strand mat (CSM) placed against the core. The specimens were all produced using vacuum infusion.

An overview of the laminates in all specimen types is provided in Table 2 . The fibre content values were obtained by burn-off tests on specimen types LA4, LB4, SA3 and SB3. For specimen types SB5 and SB10 they are assumed to be the same as for SB3. Direct measurements of laminate thickness tend to be subject to local variations; furthermore, the laminate thicknesses are less useful than the quantities of fibres when comparing failure loads for similar test specimens. The thicknesses are estimated from these fibre fractions with assumed densities of $2540 \mathrm{~kg} / \mathrm{m}^{3}$ for glass, and $1110 \mathrm{~kg} / \mathrm{m}^{3}$ and $1120 \mathrm{~kg} / \mathrm{m}^{3}$ for Dion 9102 and 9500 resins, respectively. 
Table 1. Test specimen layups and their applications in the test specimens. See Table 2 for details of the laminate layups and properties, and Table 3 for the core properties.

\begin{tabular}{|c|c|c|c|c|c|c|c|}
\hline $\begin{array}{l}\text { Layup } \\
\text { code }\end{array}$ & $\begin{array}{l}\text { Specimen } \\
\text { type }\end{array}$ & $\begin{array}{l}\text { Face } \\
\text { type }\end{array}$ & $\begin{array}{l}\text { No. of } \\
\text { layers }\end{array}$ & $\begin{array}{l}\text { Core } \\
\text { type }\end{array}$ & $\begin{array}{l}\text { Core } \\
\text { thickness } \\
(\mathrm{mm}) \\
\end{array}$ & $\begin{array}{l}\text { Damage } \\
\text { type }\end{array}$ & Load type \\
\hline LA4 & $\begin{array}{l}\text { Laminate } \\
\text { strip }\end{array}$ & A & 4 & - & - & \multirow{2}{*}{ Holes } & \multirow{2}{*}{ Tension } \\
\hline LB4 & $\begin{array}{l}\text { Laminate } \\
\text { strip }\end{array}$ & B & 4 & - & - & & \\
\hline SA3 & $\begin{array}{l}\text { Square } \\
\text { sandwich }\end{array}$ & A & 3 & H130 & 30 & \multirow{4}{*}{$\begin{array}{l}\text { Holes, } \\
\text { cracks, } \\
\text { impact }\end{array}$} & \multirow{4}{*}{ Compression } \\
\hline SB3 & $\begin{array}{l}\text { Square } \\
\text { sandwich }\end{array}$ & B & 3 & $\mathrm{H} 250$ & 30 & & \\
\hline SB5 & $\begin{array}{l}\text { Square } \\
\text { sandwich }\end{array}$ & B & 5 & $\mathrm{H} 250$ & 30 & & \\
\hline SB10 & $\begin{array}{l}\text { Square } \\
\text { sandwich }\end{array}$ & B & 10 & $\mathrm{H} 250$ & 30 & & \\
\hline
\end{tabular}

Table 2. Laminate details

\begin{tabular}{lcccccc}
\hline Layup designation: & LA4 & LB4 & SA3 & SB3 & SB5 & SB10 \\
Resin: & 9102 & 9500 & 9102 & 9500 & 9500 & 9500 \\
No. of reinforcement layers: & 4 & 4 & 3 & 3 & 5 & 10 \\
CSM present? & No & No & Yes & Yes & Yes & Yes \\
Fibre weight percent: & 72.0 & 52.9 & 72.3 & 71.9 & - & - \\
Fibre volume percent: & 52.9 & 49.5 & 53.3 & 53.0 & - & - \\
Thickness (mm): & 2.49 & 2.66 & 1.93 & 1.94 & 3.18 & 6.28 \\
\hline
\end{tabular}

In order to obtain strength reduction factors for specimens with holes, cracks and impact damage, corresponding strength values for the intact materials are needed as a reference. The tensile strengths of the laminate specimen types LA4 and LB4 without holes or cracks were measured directly in the test programme. However, it was not possible to obtain reliable results for the compressive strength of the sandwich face sheets without holes or cracks using the test arrangement as local failure for these specimens always occurred at the specimen edges. Budgetary constraints prevented further testing using more appropriate small-scale specimens. For the sandwich face sheets, compressive strengths were estimated from data available from other studies using the same reinforcements and resins, adjusted for the various fibre content values. Values of 280 $\mathrm{MPa}$ and $300 \mathrm{MPa}$ were assumed for the layups with Dion 9102 (type A) and Dion 9500 (type B) resins, respectively. In addition, for rough estimation of the wrinkling (local buckling) strengths of the sandwich face sheets an in-plane elastic modulus of $19 \mathrm{GPa}$ was assumed, also based on data for similar laminates obtained previously. 
The core materials were Divinycell PVC foams of type H130 and H250 with nominal densities of 130 and $250 \mathrm{~kg} / \mathrm{m}^{3}$, respectively. Typical properties for the core materials, taken from the manufacturer's data sheet, are given in Table 3.

Table 3. Material properties of the core materials

\begin{tabular}{lllll}
\hline Core type & $\begin{array}{c}\text { Nominal } \\
\text { density } \\
\left(\mathrm{kg} / \mathrm{m}^{3}\right)\end{array}$ & $\begin{array}{c}\text { Compressive } \\
\text { modulus } E_{c} \\
(\mathrm{MPa})\end{array}$ & $\begin{array}{c}\text { Shear } \\
\text { modulus } G_{c} \\
(\mathrm{MPa})\end{array}$ & $\begin{array}{c}\text { Compressive } \\
\text { strength } \\
(\mathrm{MPa})\end{array}$ \\
\hline PVC H130 & 130 & 170 & 50 & 3.0 \\
PVC H250 & 250 & 300 & 104 & 6.2 \\
\hline
\end{tabular}

\section{Tension tests on laminate specimens with holes}

Tensile tests were performed on 300 x $50 \mathrm{~mm}$ parallel-sided specimens of laminate type LA4 and LB4 (Tables 1 and 2) with drilled circular holes having diameters ranging from 1.5 to $24 \mathrm{~mm}$. Some additional specimens were tested without holes as a reference case. These specimens were fitted with end tabs. All specimens with holes failed in the region of the holes, remote from the ends (Figure 3). However, those without holes failed close to or under the tabs, so these results may be slight underestimates of the true strength.

The results of the tests are summarised in Table 4. For the LA4 layup, two specimens were tested with each hole size, while for the LB4 layup four specimens were tested for each hole size. The nominal strength values have been calculated by dividing the failure load by the gross cross-sectional area, based on the measured widths of the respective specimens and the thicknesses given in Table 2. For the cases with holes Table 4 shows the average failure strength, standard deviation and coefficient of variation $(\mathrm{COV})$ for the two or four similar test specimens, as appropriate. However, for the specimens without holes the maximum measured failure stress is taken as this is likely to give the most accurate estimate of the intact strength, while the standard deviation is based on the two or four test results just as for the other specimens.

Figure 4 shows the values of the strength reduction factor $R_{l}$, defined as the ratio of the strength of a specimen with a hole to that without one, plotted against the hole diameter, from the tests compared with curves in accordance with the Whitney and Nuismer criteria, equations (2) and (3). The Whitney and Nuismer curves are adjusted to the specimen width of $50 \mathrm{~mm}$ using equation (9). As Whitney and Nuismer found for glass-epoxy laminates [13], the curves based on the average stress criterion clearly give a better fit to the test data than the point stress criterion. The average stress criterion with $a_{0}$ $=4.7 \mathrm{~mm}$ gives the best fit to the data, in terms of the mean square error in the strength reduction factor values, while that with $a_{0}=4 \mathrm{~mm}$ gives a lower bound. The root mean square (RMS) error for the best fit curve is 0.014 based on the 12 average strength values, and 0.038 when based on the results for all 36 samples.

Figure 5 is based on a similar set of data, but now referred to the infinite width condition. Thus the Whitney and Nuismer curves for $a_{0}=4 \mathrm{~mm}$ and $4.7 \mathrm{~mm}$ are shown without the finite width correction, but the test results are adjusted to the infinite width 
condition by multiplying by the correction factors shown in Table 4, determined using equation (9) and assuming the characteristic length, $a_{0}=4.7 \mathrm{~mm}$.

Table 4: Results of tensile tests on laminate specimens with and without holes. Average failure strengths, standard deviations and coefficients of variation (COV) are based on two parallel samples for LA4 specimens and four parallel samples for LB4 specimens.

\begin{tabular}{lllllllll}
\hline $\begin{array}{l}\text { Layup } \\
\text { type/ } \\
\text { resin }\end{array}$ & $\begin{array}{l}\text { Hole } \\
\text { diam. } \\
(\mathrm{mm})\end{array}$ & $\begin{array}{l}\text { Average } \\
\text { failure } \\
\text { strength } \\
(\mathrm{MPa})\end{array}$ & $\begin{array}{l}\text { Std. } \\
\text { dev. } \\
(\mathrm{MPa})\end{array}$ & $\begin{array}{l}\text { COV } \\
(\%)\end{array}$ & $\begin{array}{l}\text { Strength } \\
\text { red. fact. } \\
R_{l} \text { for 50 } \\
\text { mm width }\end{array}$ & $\begin{array}{l}\text { Finite } \\
\text { width } \\
\text { corr. } \\
\text { factor }\end{array}$ & $\begin{array}{l}\text { Strength } \\
\text { adjusted to } \\
\text { inf. width } \\
(\mathrm{MPa})\end{array}$ & $\begin{array}{l}\text { Strength } \\
\text { red. fact. } \\
R_{l} \text { for inf. } \\
\text { width }\end{array}$ \\
\hline & Intact & 386 & 6.5 & 1.7 & 1.000 & 1.000 & 386 & 1.000 \\
& 1.5 & 348 & 1.3 & 0.4 & 0.901 & 1.001 & 348 & 0.902 \\
LA4 / & 3.0 & 301 & 3.6 & 1.2 & 0.781 & 1.003 & 302 & 0.783 \\
9102 & 6.0 & 257 & 8.0 & 3.1 & 0.665 & 1.014 & 260 & 0.675 \\
& 12.0 & 204 & 10.3 & 5.1 & 0.529 & 1.062 & 217 & 0.562 \\
& 24.0 & 140 & 4.6 & 3.3 & 0.361 & 1.309 & 183 & 0.474 \\
\hline & $\begin{array}{l}\text { Intact } \\
1.5\end{array}$ & 311 & 16.6 & 5.6 & 1.000 & 1.000 & 311 & 1.000 \\
LB4 / & 3.0 & 248 & 4.7 & 1.7 & 0.886 & 1.001 & 276 & 0.886 \\
9500 & 6.0 & 202 & 3.9 & 1.9 & 0.650 & 1.014 & 205 & 0.659 \\
& 12.0 & 156 & 5.3 & 3.4 & 0.500 & 1.062 & 165 & 0.532 \\
& 50.0 & 108 & 3.3 & 3.1 & 0.346 & 1.309 & 141 & 0.454 \\
\hline
\end{tabular}

\section{Compression tests on sandwich specimens with holes}

Specimens were prepared consisting of $150 \mathrm{~mm}$ square sandwich blocks with layups of types SA3, SB3, SB5 and SB10 for testing with drilled holes penetrating the entire sandwich thickness. The tests were performed with compressive loading applied to one face laminate only. To achieve this the upper and lower edges of one face laminate were machined flat and parallel and placed between two specially shaped steel fittings in a 150 $\mathrm{kN}$ universal test machine (Figure 6). As the foam core material has a much lower elastic stiffness than the face laminates it is assumed that the share of the loading taken by the core and the opposite face laminate can be neglected. Some specimens with the smaller sizes of hole failed at the loaded edge of the specimen. These were re-tested with the opposite face sheet loaded. One panel was tested without a hole in order to measure the intact strength; however, this failed at one of the loaded edges so the result must be regarded as a conservative estimate and is not used further.

The results of the tests are summarised in Table 5 and Figure 7 (left). The results of some additional tests on larger, $300 \mathrm{~mm}$ x $300 \mathrm{~mm}$ panels with $50 \mathrm{~mm}$ diameter holes are also included. Apart from the single test without a hole, all the results shown are valid results, for which the failure occurred in the region of the hole. Each of these failures occurred suddenly, with a damage region spreading across the entire width of the face laminate (Figure 6). The nominal strength values have been calculated by dividing the 
failure load by the cross-sectional area of the loaded face laminate. This is based in each case on the measured laminate width and the thickness shown in Table 2.

It was considered impossible to obtain meaningful results from tests on intact specimens using this test arrangement. Thus the assumed intact strength figures shown in Table 5 are those deduced from earlier tests as mentioned in the above section on materials and layups, i.e. $280 \mathrm{MPa}$ for the SA3 layups and $300 \mathrm{MPa}$ for the SB3, SB5 and SB10 cases. For layup SA3 the wrinkling stress is estimated to be $272 \mathrm{MPa}$, according to the Hoff and Mautner formula [28]

$$
\sigma_{\text {wrinkling }}=k_{w} \sqrt[3]{E_{f} E_{c} G_{c}}
$$

where $k_{w}$ is a constant (here taken as 0.5 ), $E_{f}$ is the Young's modulus of the face sheet (taken as $19 \mathrm{GPa}$ as stated previously) and $E_{c}$ and $G_{c}$ are the compressive modulus and shear modulus of the core given by Table 3 . This suggests that wrinkling might have slightly reduced the strength of the SA3 panels without holes, compared with the assumed strength value, though the assumed value for $k_{w}$ is a conservative value recommended by Hoff for practical design use, and includes a knock-down factor based on test results. However, as soon as holes are introduced the applied load at failure is well below that likely to cause wrinkling. For the SB panels, the wrinkling stress is significantly higher when the $E_{c}$ and $G_{c}$ values for the denser $\mathrm{H} 250$ core are assumed.

Nuismer and Labor [14] successfully applied the average stress criterion developed in [13] to GFRP laminates with holes when subjected to compressive loading, but found that the required characteristic length $a_{0}$ was 2-3 times that for the corresponding tension case. Attempts to fit this model to the results of the current tests do not give such a good fit as the tensile loading cases reported above, irrespective of the value of $a_{0}$ used. As seen in Figure 7, the average stress model with $a_{0}=19 \mathrm{~mm}$ (which is about four times the figure that gave the best fit for tension loading) gives a best fit for the compression case, the RMS error being 0.050 based on 24 specimens. (In this evaluation the result of the test on the intact SB10 panel is omitted.) The curve with $a_{0}=$ $15 \mathrm{~mm}$ (omitted for clarity from Figure 7) gives a reasonable lower bound approximation for all but one of the SB type panels, and $a_{0}=12 \mathrm{~mm}$ gives an approximate lower bound for all panels, apart from one of the SA type panels. Finally, $a_{0}=9 \mathrm{~mm}$ gives a lower bound for all panels.

Note that in Table 5 and Figure 7 the "corrected" strength values have been adjusted for the finite size of the square sandwich specimens as described using the factor defined in equation (11).

The somewhat irregular reduction of $R_{l}$ with increasing hole size may be partly due to delamination damage introduced during the machining process, or other production irregularities. These results differ somewhat from those obtained by Zenkert et al. [2] for carbon fibre reinforced face laminates, which show a continuing, gradual drop in strength as the hole diameter is increased, and resemble more closely the variation given by the Whitney and Nuismer model. Note, however, that the results for the SB specimens with differing face sheet thicknesses (SB3, SB5, SB10) do not show any clear thickness dependence. 
Table 5. Results of in-plane compression tests on sandwich specimens with circular, machined holes.

\begin{tabular}{|c|c|c|c|c|c|c|c|}
\hline \multirow{2}{*}{$\begin{array}{l}\text { Layup } \\
\text { type }\end{array}$} & \multirow{2}{*}{$\begin{array}{l}\text { Hole } \\
\text { diameter } \\
(\mathrm{mm})\end{array}$} & \multirow{2}{*}{$\begin{array}{l}\text { Specimen } \\
\text { width } \\
(\mathrm{mm})\end{array}$} & \multirow{2}{*}{$\begin{array}{l}\text { Failure } \\
\text { load } \\
(\mathrm{kN})\end{array}$} & \multirow{2}{*}{$\begin{array}{l}\text { Finite } \\
\text { width } \\
\text { corr. } \\
\text { factor }\end{array}$} & \multicolumn{2}{|c|}{$\begin{array}{l}\text { Failure stresses } \\
(\mathrm{MPa})\end{array}$} & \multirow{2}{*}{$\begin{array}{l}\text { Strength } \\
\text { red. fact. } \\
R_{l} \text { for inf. } \\
\text { width }\end{array}$} \\
\hline & & & & & $\begin{array}{l}\text { From } \\
\text { test }\end{array}$ & $\begin{array}{l}\text { For inf. } \\
\text { width }\end{array}$ & \\
\hline \multirow{6}{*}{$\begin{array}{l}\text { SA3 / } \\
9102 \text { / } \\
\text { H130 }\end{array}$} & $10.0^{\mathrm{a}}$ & 150.4 & 52.0 & 1.004 & 179 & 181 & 0.643 \\
\hline & 22.7 & 150.2 & 48.1 & 1.023 & 166 & 170 & 0.602 \\
\hline & 33.0 & 150.8 & 43.7 & 1.051 & 151 & 158 & 0.556 \\
\hline & 40.2 & 149.2 & 42.5 & 1.080 & 148 & 160 & 0.560 \\
\hline & 50.5 & 149.1 & 43.0 & 1.133 & 150 & 170 & 0.593 \\
\hline & 50.0 & 298 & $85.0^{\mathrm{b}}$ & 1.031 & 148 & 153 & 0.538 \\
\hline \multirow{5}{*}{$\begin{array}{l}\text { SB3 / } \\
9500 / \\
\mathrm{H} 250\end{array}$} & 10.0 & 150.5 & $73.6^{c}$ & 1.004 & 253 & 254 & 0.842 \\
\hline & 22.0 & 150.1 & 58.6 & 1.022 & 202 & 206 & 0.680 \\
\hline & 33.1 & 150.2 & 54.6 & 1.051 & 188 & 197 & 0.647 \\
\hline & 40.0 & 150.2 & 48.0 & 1.078 & 165 & 178 & 0.581 \\
\hline & 50.0 & 300 & $100^{\mathrm{d}}$ & 1.030 & 172 & 177 & 0.583 \\
\hline \multirow{7}{*}{$\begin{array}{l}\text { SB5 / } \\
9500 / \\
\text { H250 }\end{array}$} & 10.0 & 150.5 & 104.3 & 1.004 & 218 & 219 & 0.727 \\
\hline & 32.0 & 150 & 94.0 & 1.048 & 197 & 207 & 0.678 \\
\hline & 32.0 & 150 & 96.0 & 1.048 & 201 & 211 & 0.692 \\
\hline & 40.2 & 149.4 & 92.0 & 1.079 & 194 & 209 & 0.684 \\
\hline & 50.5 & 150.4 & 76.0 & 1.130 & 159 & 180 & 0.586 \\
\hline & 50.0 & 299 & 155.0 & 1.031 & 163 & 168 & 0.553 \\
\hline & 50.0 & 300 & 157.0 & 1.030 & 165 & 170 & 0.558 \\
\hline \multirow{7}{*}{$\begin{array}{l}\text { SB10 / } \\
9500 \text { / } \\
\text { H250 }\end{array}$} & 0 & 150 & 235.2 & 1.000 & $250^{e}$ & $250^{e}$ & 0.832 \\
\hline & 20 & 149.6 & 196.9 & 1.018 & 210 & 213 & 0.705 \\
\hline & 32 & 149.3 & 170.1 & 1.048 & 181 & 190 & 0.624 \\
\hline & 40 & 149.6 & 149.6 & 1.078 & 159 & 172 & 0.561 \\
\hline & 50 & 150 & 151.6 & 1.128 & 161 & 181 & 0.592 \\
\hline & 50 & 150 & 169.6 & 1.128 & 180 & 203 & 0.662 \\
\hline & 50 & 300 & 295.0 & 1.030 & 157 & 161 & 0.530 \\
\hline
\end{tabular}

a The hole was surrounded by delamination damage to a diameter of $14 \mathrm{~mm}$; this value is used in the figures.

${ }^{\mathrm{b}}$ This was the second side tested. The first side failed prematurely at $73.5 \mathrm{kN}$.

${ }^{\mathrm{c}}$ This was the second side tested. The first side failed prematurely at $59.7 \mathrm{kN}$.

d Approximate value.

${ }^{\mathrm{e}}$ Measured, but failure at loaded edge of panel.

In Figure 7 and Table 5 it is seen that the strength reduction factor $R_{l}$ for specimens with $50 \mathrm{~mm}$ holes appears somewhat smaller for the $300 \mathrm{~mm}$ panels than for the $150 \mathrm{~mm}$ panels, in spite of the adjustments for finite panel width, though the highest $R_{l}$ value for the $300 \mathrm{~mm}$ panels is close to the lowest value for the $150 \mathrm{~mm}$ panels. A possible reason for this difference is inadequacy in the applied finite width correction factors; for these panels these factors are based on the stress values at the edge of the 
hole, rather than the average stress over the characteristic length $a_{0}$. Figure 2 shows that the correction factor increases with $a_{0} / w$, and for strip specimens it is somewhat smaller if based on the average stress than on the stress at the edge of the hole (represented by the curve for $a_{0} / w=0$ ). For $50 \mathrm{~mm}$ holes, the $300 \mathrm{~mm}$ panels have $2 R / w=0.167$, while the $150 \mathrm{~mm}$ panels have $2 R / w=0.333$, which gives a significantly larger correction factor. Thus, if the correction had been based on the average stress over the characteristic length instead of the stress at the edge of the hole, the correction would have been reduced more for the $150 \mathrm{~mm}$ panels than for the $300 \mathrm{~mm}$ panels. This suggests that the $150 \mathrm{~mm}$ panels with large $(50 \mathrm{~mm})$ holes may be over-compensated for the finite panel size, and moreso than for the $300 \mathrm{~mm}$ panels. Thus the curves for the $150 \mathrm{~mm}$ panels should probably fall more steeply for large hole diameters. In view of this uncertainty, for the square panels more reliance should be placed on the lower bound curves than the "best fit" curves.

There remains some uncertainty about the value of the intact strength for these laminates. This aspect requires further investigation, as does the possible identification of a suitable alternative micro-mechanical model that might give a better description of the behaviour. It should also be noted that the hole diameters considered were appreciably larger than those for the laminates tested in tension.

\section{Impact of sandwich specimens with a blunt object}

\section{Main test programme}

Compression tests were performed on a series of $300 \mathrm{~mm}$ square sandwich panels with face sheets that were damaged by a $20 \mathrm{~kg}$ impactor with a hemispherical tip of radius $12.5 \mathrm{~mm}$ (designated impactor A). The impactor was dropped from heights between 0.5 $\mathrm{m}$ and $2.0 \mathrm{~m}$ (though for a few tests the drop height was not recorded). The tests can be divided into two groups: those in which the impact resulted in a hole (with a surrounding region of delamination) and those in which the only visible damage was delamination and a slight dent. Some typical cases are shown in Figure 8. The width of the delaminated region and (where applicable) the hole were measured before compression testing. As the reinforcement was glass, the width of the delaminated area could be measured visually. On a ship in service the surface would be painted so a suitable non-destructive inspection method using, for example, a pulse-echo ultrasound probe would be needed. The results are summarised in Table 6 (which also includes results from supplementary tests with an alternative impactor, designated type $\mathrm{B}$, described in the next section).

The results are plotted in Figure 9, which shows the strength reduction factor from the tests plotted against the delamination size. It is clear that the best correlation between residual strength and damage size is obtained if the damage size is represented by the delamination width rather than the hole width, since some of the panels did not develop holes but did experience reduction of strength due to the impact. All results are adjusted to correspond to an infinite panel size using the factor defined by equation (11). The curves for the Whitney and Nuismer average stress criterion for $a_{0}=9 \mathrm{~mm}, 12 \mathrm{~mm}$ and $15 \mathrm{~mm}$ are also shown. It is seen that the test results resemble those for the panels with machined holes of similar size to the delaminations, with the average stress model for $a_{0}$ 
$=9 \mathrm{~mm}$ again providing a lower bound for all the test results. However, $a_{0}=15 \mathrm{~mm}$ gives the best fit, with an RMS error of 0.054 based on the 13 samples with the correct failure mode.

In Figure 9, the test results shown with open symbols correspond to the cases where the impactor did not penetrate the face sheet but only caused a delamination. For these panels the compression tests produced failures at the loaded specimen edges rather than at the damage location; had the edges been reinforced to prevent these failures the failure loads would presumably have been higher.

Table 6: In-plane compression tests on sandwich specimens with blunt impact damage.

\begin{tabular}{|c|c|c|c|c|c|c|c|c|c|c|}
\hline \multirow{2}{*}{$\begin{array}{l}\text { Layup } \\
\text { type }\end{array}$} & \multirow{2}{*}{$\begin{array}{l}\text { Im- } \\
\text { pact } \\
\text { type }\end{array}$} & \multirow{2}{*}{$\begin{array}{l}\text { Drop } \\
\text { ht. } \\
\text { (m) }\end{array}$} & \multirow{2}{*}{$\begin{array}{l}\text { Hole } \\
\text { dia. } \\
(\mathrm{mm})\end{array}$} & \multirow{2}{*}{$\begin{array}{l}\text { De- } \\
\text { lam. } \\
\text { width } \\
(\mathrm{mm})\end{array}$} & \multirow{2}{*}{$\begin{array}{l}\text { Spec- } \\
\text { imen } \\
\text { width } \\
(\mathrm{mm})\end{array}$} & \multirow{2}{*}{$\begin{array}{l}\text { Fail. } \\
\text { load } \\
(\mathrm{kN})\end{array}$} & \multirow{2}{*}{$\begin{array}{l}\text { Finite } \\
\text { width } \\
\text { corr. } \\
\text { factor }\end{array}$} & \multicolumn{2}{|c|}{$\begin{array}{l}\text { Fail. stresses } \\
\text { (MPa) }\end{array}$} & \multirow{2}{*}{$\begin{array}{l}\text { Strength } \\
\text { red. fact. } \\
R_{l} \text { for inf } \\
\text { width }\end{array}$} \\
\hline & & & & & & & & $\begin{array}{l}\text { From } \\
\text { test }\end{array}$ & $\begin{array}{l}\text { For inf. } \\
\text { width }\end{array}$ & \\
\hline \multirow{5}{*}{$\begin{array}{l}\text { SA3 / } \\
9102 / \\
\text { H130 }\end{array}$} & A & . & 0 & 15 & 300 & 102 & 1.000 & $177^{\mathrm{C}}$ & 177 & 0.631 \\
\hline & A & a & 0 & 25 & 300 & 106 & 1.002 & $184^{\mathrm{c}}$ & 184 & 0.657 \\
\hline & A & 0.5 & 22 & 33 & 300 & 81.7 & 1.005 & 141 & 142 & 0.508 \\
\hline & A & 1 & 24 & 39 & 300 & 77.2 & 1.008 & 134 & 135 & 0.481 \\
\hline & $\mathrm{A}$ & 1 & 25 & 40 & 299.5 & 80.1 & 1.009 & 139 & 140 & 0.501 \\
\hline \multirow{4}{*}{$\begin{array}{l}\text { SB3 / } \\
9500 / \\
\mathrm{H} 250\end{array}$} & $\mathrm{~A}$ & a & 0 & 25 & 300 & 97 & 1.002 & $167^{\circ}$ & 167 & 0.558 \\
\hline & A & 0.5 & 23 & 37 & 300 & 95.1 & 1.007 & 164 & 165 & 0.550 \\
\hline & A & 1 & 23 & 41 & 300 & 91.2 & 1.010 & 157 & 158 & 0.528 \\
\hline & $\mathrm{A}$ & 1 & 22 & 40 & 300 & 113.1 & 1.009 & 195 & 196 & 0.655 \\
\hline \multirow{6}{*}{$\begin{array}{l}\text { SB5 / } \\
9500 / \\
\mathrm{H} 250\end{array}$} & $\mathrm{~B}$ & $\mathrm{~b}$ & 0 & 71 & 300 & 200.7 & 1.042 & 210 & 219 & 0.731 \\
\hline & B & $\mathrm{b}$ & 0 & 70 & 150 & 106.3 & 1.271 & 223 & 283 & 0.945 \\
\hline & B & $\mathrm{b}$ & 0 & 63 & 150 & 104.5 & 1.199 & 219 & 263 & 0.876 \\
\hline & A & 0.5 & 17 & 47 & 297.5 & 150.3 & 1.014 & 159 & 161 & 0.537 \\
\hline & A & 1 & 24 & 42 & 298.5 & 135.2 & 1.011 & 142 & 144 & 0.480 \\
\hline & $\mathrm{A}$ & 1 & 24 & 49 & 299.5 & 141.8 & 1.016 & 149 & 151 & 0.504 \\
\hline \multirow{6}{*}{$\begin{array}{l}\mathrm{SB} 10 / \\
9500 / \\
\mathrm{H} 250\end{array}$} & $\mathrm{~B}$ & $\mathrm{~b}$ & 0 & 76 & 300 & 344 & 1.050 & 183 & 192 & 0.639 \\
\hline & B & $\mathrm{b}$ & 0 & 63 & 149.6 & 188.8 & 1.200 & 201 & 241 & 0.804 \\
\hline & A & 2 & 23 & 55 & 300 & 294.3 & 1.021 & 156 & 159 & 0.532 \\
\hline & A & 1 & 16 & 43.5 & 298 & 337.2 & 1.012 & 180 & 182 & 0.607 \\
\hline & A & 2 & 25 & 54 & 300 & 277.5 & 1.020 & 147 & 150 & 0.501 \\
\hline & A & 1 & 15 & 55 & 299.5 & 311 & 1.022 & 165 & 169 & 0.563 \\
\hline
\end{tabular}

${ }^{a}$ Drop height not recorded

${ }^{\mathrm{b}}$ Repeated impacts, various drop heights

${ }^{c}$ Failure occurred at specimen ends. 


\section{Additional tests with a smaller impactor}

Further tests were performed, in which an object having mass $12.5 \mathrm{~kg}$ was dropped repeatedly onto a $15 \mathrm{~mm}$ diameter steel ball (designated impactor B) attached loosely to the sandwich face sheet, to provide more data for damage consisting of delamination without fibre breakage and penetration of the face sheet. These results are included in Table 6 and in Figure 10 (left), in which they are marked off by the circle. It is seen that the failure loads, and deduced values of strength reduction factor, corresponding to these points lie well above those for tests with penetration of the face sheet produced by impactor A. Use of the Whitney and Nuismer approach based on delamination width thus seems very conservative for these cases. It is likely that the delaminations do not affect all of the laminate plies, so that more knowledge is needed about the depth of the damage in order to explore possible models for these cases.

Closer inspection of the results in Table 6 reveals that the $150 \mathrm{~mm}$ square panels appear to give much higher strengths (in terms of applied stresses) than the $300 \mathrm{~mm}$ square panels. This suggests that the way of treating the stress distributions is inappropriate. In addition to the possible over-compensation for the finite panel size for $150 \mathrm{~mm}$ square panels, mentioned earlier in connection with panels having circular holes, it may be argued that, since these delaminations do not produce a break in any of the plies, the stress concentration around the damaged area will be significantly less than would occur if there were a real discontinuity. This suggests that it may be more appropriate in these cases to estimate the stress at the damage by simply dividing the applied load by the gross cross-sectional area, and ignoring the finite specimen size effect. The effect of this change of approach is shown in Figure 10 (right): the data points are much more consistent with the other cases, and the difference between large and small panels is very much reduced.

Whether this simple approach is in any way consistent with using the Whitney and Nuismer average stress criterion applied to the region just outside the delaminated area is questionable, so this type of damage requires further study. It should be noted that damage consisting of complete separation (debond/disbond) of the face sheet from the core has been addressed using totally different fracture mechanics based approaches [8].

\section{Compression tests on sandwich specimens with machined slits/cracks}

In order to provide local strength reduction data for compression-loaded face sheet laminates with machined crack-like apertures and with damage due to contact with a sharp object that penetrates the face sheet, in-plane compression tests have been performed on a series of sandwich specimens with both machined slits and real damage from contact with a sharp object. The test specimens were similar to those used for the tests on the effects of holes and blunt impact damage.

The specimens with machined slits were prepared by drilling a hole at the centre of the intended slit and then using a powered jig saw to cut a slit extending to each side of 
the hole. The tests were performed with compressive loading applied to one face laminate only, as for the specimens with circular holes. Figure 11 shows (left) the test arrangement with a specimen installed and (right) the same specimen after testing.

Only eight specimens of this type were tested. The results are shown in Table 7 and Figure 12. The specimens developed very small cracks/damage zones first. The cracks then propagated in jumps as the loading was increased further, with a damage region spreading across the entire width of the face laminate (Figure 11, right). The intact laminate strength values were assumed to be the same as those assumed for the specimens with holes and blunt impactor damage.

The resulting strength reduction values from the tests are shown in Figure 12. Here the test results have been corrected for finite width of the specimen according to the Koiter formula [26], equation (11). Also shown are the curves based on the Whitney and Nuismer average stress criterion for cracks, based on the two cases $a_{0}=7.8 \mathrm{~mm}$ and $a_{0}=$ $6.5 \mathrm{~mm}$. The best fit is given by $a_{0}=7.8 \mathrm{~mm}$, with an RMS error of 0.024 based on 8 specimens, while $a_{0}=6.5 \mathrm{~mm}$ gives a lower bound to the test data. The value for $a_{0}$ should, according to Whitney and Nuismer, be a material property and independent of the geometry, and thus have the same value as for circular holes (and impact damage). It was concluded earlier that a value of $a_{0}=9 \mathrm{~mm}$ gave a good lower bound to the results for both holes and blunt impact damage (if the delamination width, rather than hole diameter, is used in the case of blunt impact), but it is clear that a somewhat smaller value, $a_{0}=6.5$ mm must be used to give a lower bound in the current case of machined cracks. This is also closer to the value found for laminates with holes under tensile loading.

Table 7. Results of in-plane compression tests on sandwich specimens with machined slits/cracks.

\begin{tabular}{|c|c|c|c|c|c|c|c|}
\hline \multirow{2}{*}{$\begin{array}{l}\text { Layup } \\
\text { type }\end{array}$} & \multirow{2}{*}{$\begin{array}{l}\text { Crack } \\
\text { length } \\
(\mathrm{mm})\end{array}$} & \multirow{2}{*}{$\begin{array}{l}\text { Specimen } \\
\text { width } \\
(\mathrm{mm})\end{array}$} & \multirow{2}{*}{$\begin{array}{l}\text { Failure } \\
\text { load } \\
(\mathrm{kN})\end{array}$} & \multirow{2}{*}{$\begin{array}{l}\text { Finite } \\
\text { width } \\
\text { corr. } \\
\text { factor }\end{array}$} & \multicolumn{2}{|c|}{$\begin{array}{l}\text { Failure stresses } \\
(\mathrm{MPa})\end{array}$} & \multirow{2}{*}{$\begin{array}{l}\text { Strength } \\
\text { red. fact. } \\
R_{l} \text { for inf. } \\
\text { width }\end{array}$} \\
\hline & & & & & $\begin{array}{l}\text { From } \\
\text { test }\end{array}$ & $\begin{array}{l}\text { For inf. } \\
\text { width }\end{array}$ & \\
\hline \multirow{3}{*}{$\begin{array}{l}\text { SA3 / } \\
9102 / \\
\text { H130 }\end{array}$} & 34.2 & 150.4 & 34.7 & 1.028 & 119.9 & 123.2 & 0.440 \\
\hline & 44.0 & 151.2 & 28.1 & 1.048 & 96.5 & 101.1 & 0.361 \\
\hline & 31.0 & 149.8 & 34.5 & 1.022 & 119.6 & 122.3 & 0.437 \\
\hline \multirow{3}{*}{$\begin{array}{l}\text { SB3 / } \\
9500 \text { / } \\
\text { H250 }\end{array}$} & 15.9 & 150.0 & 48.5 & 1.005 & 166.9 & 167.8 & 0.559 \\
\hline & 34.4 & 150.5 & 38.2 & 1.028 & 131.0 & 134.7 & 0.449 \\
\hline & 40.0 & 150.3 & 30.7 & 1.039 & 105.5 & 109.6 & 0.365 \\
\hline \multirow{2}{*}{$\begin{array}{l}\mathrm{SB5} / \\
9500 \text { / } \\
\mathrm{H} 250\end{array}$} & 15.9 & 150.3 & 84.6 & 1.005 & 177.1 & 178.0 & \multirow{2}{*}{$\begin{array}{l}0.593 \\
0.463\end{array}$} \\
\hline & 34.9 & 150 & 64.4 & 1.029 & 135.1 & 139.0 & \\
\hline
\end{tabular}




\section{Impact of sandwich specimens with a sharp object}

Compression tests were performed on $300 \mathrm{~mm}$ and $150 \mathrm{~mm}$ square sandwich panels with face sheets that were damaged by a $12.5 \mathrm{~kg}$ impactor fitted with one of the two wedgeshaped tips shown in Figure 13. The width of both the penetrated region and the delaminated region were measured before compression testing. The test method was as for the panels with holes, blunt impact damage and machined slits/cracks. The results are summarised in Table 8, in which the finite width correction factor is applied using the Koiter formula, equation (11). Some typical examples of the damage produced, and the subsequent failures, are shown in Figure 14.

Table 8. Results of in-plane compression tests on sandwich specimens with damage due to impact with a sharp object.

\begin{tabular}{|c|c|c|c|c|c|c|c|c|}
\hline \multirow[b]{2}{*}{$\begin{array}{l}\text { Layup } \\
\text { type }\end{array}$} & \multirow{2}{*}{$\begin{array}{l}\text { Crack } \\
\text { length } \\
(\mathrm{mm})\end{array}$} & \multirow{2}{*}{$\begin{array}{l}\text { Delam. } \\
\text { width } \\
(\mathrm{mm})\end{array}$} & \multirow{2}{*}{$\begin{array}{l}\text { Specimen } \\
\text { width } \\
(\mathrm{mm})\end{array}$} & \multirow{2}{*}{$\begin{array}{l}\text { Failure } \\
\text { load } \\
(\mathrm{kN})\end{array}$} & \multirow{2}{*}{$\begin{array}{l}\text { Finite } \\
\text { width } \\
\text { corr. } \\
\text { factor }\end{array}$} & \multicolumn{2}{|c|}{$\begin{array}{l}\text { Failure stresses } \\
(\mathrm{MPa})\end{array}$} & \multirow{2}{*}{$\begin{array}{l}\text { Strength } \\
\text { red. fact. } \\
R_{l} \text { for inf. } \\
\text { width }\end{array}$} \\
\hline & & & & & & $\begin{array}{l}\text { From } \\
\text { test }\end{array}$ & $\begin{array}{l}\text { For } \\
\text { inf. } \\
\text { width }\end{array}$ & \\
\hline \multirow{2}{*}{$\begin{array}{l}\text { SA3 / } \\
9102 \text { / } \\
\text { H130 }\end{array}$} & 42 & 51 & 298 & 68.1 & 1.010 & 118.7 & 119.9 & 1.015 \\
\hline & 44 & 60 & 150 & 33.3 & 1.048 & 115.3 & 120.9 & 1.100 \\
\hline \multirow{2}{*}{$\begin{array}{l}\text { SB3 / } \\
9500 \text { / } \\
\text { H250 }\end{array}$} & 35 & 46 & 300 & $85.5^{\mathrm{a}}$ & 1.007 & 147.1 & 148.1 & 0.494 \\
\hline & 28 & 43 & 150 & 46.8 & 1.018 & 161.1 & 164.0 & 0.547 \\
\hline \multirow{2}{*}{$\begin{array}{l}\text { SB5 / } \\
9500 \text { / } \\
\text { H250 }\end{array}$} & 37 & 50 & 298.5 & 127.5 & 1.008 & 134.4 & 135.4 & 0.451 \\
\hline & 40 & 53 & 150 & 64.3 & 1.039 & 134.8 & 140.1 & 0.467 \\
\hline SB10/ & 23 & $50 / 65$ & 300 & 280 & 1.003 & 148.5 & 149.0 & 0.497 \\
\hline 9500 / & 23 & 55 & 298.5 & 273 & 1.003 & 145.6 & 146.0 & 0.487 \\
\hline $\mathrm{H} 250$ & 23 & $52 / 65$ & 149 & 137.3 & 1.012 & 146.7 & 148.4 & 0.495 \\
\hline
\end{tabular}

${ }^{a}$ Failure occurred at specimen end.

The resulting strength reduction factors, in accordance with the data in Table 8, are shown in Figure 15 (left), in which $R_{l}$ is plotted against the length of the penetrated region of the face sheet. Figure 15 (right) shows the results when plotted against the width of the delaminated area. (Here the finite width correction has been applied to the failure load based on the width of the delaminated area rather than the penetrated region.) It is seen that, in contrast to the case with blunt impact damage, the best correlation between residual strength and damage size is obtained if the damage size is represented by the length of the penetrated region rather than the delamination width.

Figure 15 includes the curves for the average stress criterion with $a_{0}=6.5 \mathrm{~mm}$ and $9.2 \mathrm{~mm}$, and can be compared with Figure 12. The curve based on $a_{0}=9.2 \mathrm{~mm}$ gives the best fit, with an RMS error of 0.034 based on 9 specimens. As for the machined slits/cracks, the curve based on $a_{0}=6.5 \mathrm{~mm}$ gives a good lower bound to the test results. 
This confirms that machined cracks give an adequate representation of the sharp impact damage.

\section{Quantification of scatter and curve fitting errors}

For each case considered (holes/tension, holes/compression, cracks/compression, blunt or sharp impact/compression) the best fit strength reduction curve, as represented by the Whitney and Nuismer failure model, has been established together with the RMS error between the test results and the best fit curve. These parameters are summarised in Table 9. The best fit curves have been presented in the respective figures.

Table 9 Statistical data from tests

\begin{tabular}{|c|c|c|c|c|}
\hline \multirow[t]{2}{*}{ Test case } & \multirow{2}{*}{$\begin{array}{l}\text { No. of } \\
\text { samples }\end{array}$} & \multirow{2}{*}{$\begin{array}{l}\text { Min. } \\
\text { RMS } \\
\text { error } \\
\text { in } R_{l}\end{array}$} & \multicolumn{2}{|c|}{$a_{0}$ value $(\mathrm{mm})$} \\
\hline & & & Best fit & $\begin{array}{l}\text { Lower } \\
\text { bound }\end{array}$ \\
\hline Hole in tension based on means for parallels & 12 & 0.014 & 4.7 & 4.0 \\
\hline Hole in tension based on individual tests & 36 & 0.038 & 4.7 & $3.4 *$ \\
\hline Hole in compression & 24 & 0.050 & 19 & 9 or 12 \\
\hline Blunt impact, compression & 13 & 0.054 & 15 & 9 \\
\hline Machined crack, compression & 8 & 0.024 & 7.8 & 6.5 \\
\hline Sharp impact, compression & 9 & 0.034 & 9.2 & 6.5 \\
\hline
\end{tabular}

* Not shown in the figures.

The table shows that for compression loading the RMS errors for the cases of machined circular holes and blunt impacts are highest. The machined cracks have the lowest RMS error, followed by the sharp impacts. For the holes in tension, the best fit curve is not significantly affected if taking all the individual test results is replaced by taking the mean result for each set of parallels, but the apparent scatter is reduced by the averaging process, as might be expected.

\section{Recommended strength reduction curves based on average stress criterion}

Based on the data presented in the previous sections, the local strength reduction curves shown in Figures 16 and 17 are proposed for use in the assessment of local impact damage to the face sheets of sandwich panels having layups of the types considered in this study. They can also be applied in cases of machined circular holes and cracks.

Figure 16 is based on the Whitney and Nuismer curve for $a_{0}=4 \mathrm{~mm}$ and applies to cases of circular holes in panels with face sheets exposed to in-plane tension. Cases with actual impact damage were not tested, but it is postulated that for blunt impacts the same curve can be applied but is likely to be conservative. As the presence of the core is not expected to affect these results significantly, the same curve may be used for panels 
with all foam cores. Note that, for large holes, the curve approaches $R_{l}=1 / 3$, the value for homogeneous, isotropic materials, and it is convervative to use this value for all cases.

Figure 17 applies to cases with compressive in-plane loading of sandwich face sheets. The left-hand figure should be used for circular holes and blunt impacts. For machined holes it is recommended that the curve for $a_{0}=9 \mathrm{~mm}$ be used for type SA layups; for type SB layups the curve for $a_{0}=12 \mathrm{~mm}$ may be used, though one of the test results lay below this curve. Alternatively the curve with $a_{0}=9 \mathrm{~mm}$ may be used, but this is likely to be conservative. For blunt impacts the curve with $a_{0}=9 \mathrm{~mm}$ should be used for both laminate types, the damage size being represented by the delamination width. For cases with cracks or sharp impacts, the right-hand figure should be used. This is based on the Whitney and Nuismer crack model with $a_{0}=6.5 \mathrm{~mm}$. Impacts caused by sharp objects can often be distinguished by the visible presence of cut fibres, but nondestructive inspection may be needed for clarification; in cases of doubt the more conservative sharp impact curve should be used.

For sandwich faces made with alternative reinforcements and/or matrix materials, it is recommended that strength reduction curves be generated using the same approach as in the present study. In such cases it may be sufficient to perform a more limited series of tests simply to check whether the results, in terms of strength reduction factors, are significantly different from those presented above. In performing such work it is important to give careful consideration to the determination of the intact strength to use as a reference. This may present challenges, especially for cases with compressive loading.

The stress distributions assumed in the Whitney and Nuismer criteria are based on the assumption of isotropic (or quasi-isotropic) material behaviour. The criteria can be extended to orthotropic laminates using the analysis of Lekhnitskii [29]; finite width correction factors are available from Tan [30] for strip specimens and, for some cases, by Hong and Crews [24] for square specimens. Note that, for orthotropic laminate layups, it will be important to ensure that the test specimens are loaded in the most relevant direction relative to the fibre orientations. The use of more advanced numerical approaches to generate strength reduction curves [18-20] may also be worth pursuing so as to reduce the need for physical testing of samples. However, the reduced need for physical testing will be to some extent offset by the increased effort required for numerical analysis, and some testing will always be needed to validate the more advanced models.

\section{Conclusions}

Local strength reduction curves have been proposed for sandwich panels subject to damage in the form of face sheet holes, cracks and impact damage for a series of sandwich layups involving non-crimp, glass fabrics, vinylester matrix materials and PVC foam cores. The curves are based on physical testing and curve fitting using the Whitney and Nuismer average stress criterion applied to circular hole and transverse crack models. 
For blunt impacts with or without face sheet penetration the equivalent hole diameter must be based on the delamination width, rather than the size of the penetration. For some low-level blunt impacts producing delamination without fibre breakage, this approach appears to be very conservative and it appears to be more appropriate to ignore the stress concentration effect around the damage. However, such cases require further study.

Values of the characteristic length $a_{0}$ for compression loading with holes and blunt impacts are 2-3 times those for tension, as observed by Nuismer and Labor. The characteristic length is also larger for compression loading with cracks and slits than for the same cases with tensile loading, but by a smaller ratio.

Difficulties in determining the intact strengths have led to some uncertainty in these results.

\section{Acknowledgments}

The test specimens were manufactured by Umoe Mandal AS. Additional material data were provided by FiReCo AS. The support of these organisations is gratefully acknowledged. The tests on specimens with holes and impact damage were performed at NTNU by Postdoctoral Research Fellow Anthonippillai Antonarulrajah and MSc. students Arve Sinnerud and Aslanbek Sjamsutdinov, assisted by laboratory staff Iver Johnsen, Per Nordtug and Børge Holen.

\section{Declaration of Conflicting Interests}

The authors declare that there is no conflict of interest.

\section{Funding}

The research was funded by the Royal Norwegian Navy Materiel Command (now the Naval Systems Division of the Norwegian Defence Materiel Agency) while the first author was employed at Det Norske Veritas (DNV).

\section{References}

1. Hayman B. Defect and damage assessment for ships built in FRP sandwich. RINA Conference on High Speed Craft: Design and Operation, Royal Institution of Naval Architects, London, UK, 17-18 November 2004, pp. 31-40.

2. Zenkert D, Shipsha A, Bull P et al. Damage Tolerance Assessment of Composite Sandwich Panels with Localised Damage. Compos Sci Technol 2005; 65(15-16): 2597-2611.

3. Hayman B. Approaches to damage assessment and damage tolerance for FRP sandwich structures. J Sandwich Struct Mater 2007; 9 (6): 571-596.

4. Sutherland LS. A review of impact testing on marine composite materials: Part IMarine impacts on marine composites. Compos Struct 2018; 188: 197-208. 
5. Sutherland LS. A review of impact testing on marine composite materials: Part III Damage tolerance and durability. Compos Struct 2018; 188: 512-518.

6. Hayman B, Echtermeyer AT and Berggreen C. Effects of face sheet damage on residual strength of GRP sandwich panels in naval ships. 9th Int. Conf. on Sandwich Structures, Pasadena, CA, USA, 14-16 June 2010.

7. B. Hayman B and Echtermeyer AT. Effects of Face Sheet Holes and Impact Damage on Residual Strength of GRP Sandwich Panels in Naval Ships. 10th Int. Conf. on Sandwich Structures, Nantes, France, 27-29 August 2012.

8. Moslemian R, Quispitupa A, Berggreen C et al. Failure of Uniformly Compression Loaded Debond Damaged Sandwich Panels - an Experimental and Numerical Study. J Sandwich Struct Mater 2012; 14 (3): 297-324.

9. Soutis C, Curtis P, Fleck NA. Compressive failure of notched carbon fibre composites. Proc R Soc London 1993; 440 (1909): 241-256.

10. Soutis C, Fleck NA, Smith PA. Failure prediction technique for compression loaded carbon fibre-epoxy laminate with a single hole. J Compos Mater 1991; 24: 14761498.

11. Soutis $\mathrm{C}$ and Curtis P. Prediction of the post-impact compressive strength of CFRP laminated composites. Compos Sci Technol 1996; 56 :677-684.

12. Sutcliffe M, Xin A, Fleck NA et al. Composite compressive strength modeller. Engineering Department, Cambridge University, UK, 1999.

13. Whitney JM and Nuismer RJ. Stress fracture criteria for laminated composites containing stress concentrations. J Compos Mater 1974; 8: 253-265.

14. Nuismer RJ and Labor JD. Applications of the average stress failure criterion: Part II - Compression. J Compos Mater 1979; 13: 49-60.

15. Hashin and Rotem A cumulative damage theory of fatigue failure, J Mater Sci 1978; 34: 147-160.

16. Puck A and Schürmann H. Failure Analysis of FRP laminates by means of physically based phenomenological models. Compos Sci Technol 2002; 62 (12-13): 1633-1662.

17. Knops M. Analysis of Failure in Fiber Polymer Laminates: The Theory of Alfred Puck. Springer, 2008.

18. Sleight DW. Progressive Failure Analysis Methodology for Laminated Composite Structures. Report, NASA/TP-1999-209107, USA, 1999

19. Rose CA, Dávila CG and Leone FA. Analysis Methods for Progressive Damage of Composite Structures. Report, NASA/TM-2013-218024, USA, 2013.

20. NASA CompDam - Deformation Gradient Decomposition (DGD, https://github.com/nasa/CompDam_DGD. (2019, accessed 27 January 2019).

21. Peterson RE. Stress Concentration Factors. New York: Wiley, 1974.

22. Howland RCJ. On the Stresses in the Neighbourhood of a Circular Hole in a Strip under Tension. Philos Tran R Soc London, Ser A 1930; 229: 49-86.

23. Heywood RB. Designing by Photoelasticity. London: Chapman and Hall, 1952.

24. Hong CS and Crews JH Jr. Stress-Concentration Factors for Finite Orthotropic Laminates With a Circular Hole and Uniaxial Loading. NASA Technical Paper 1469, National Aeronautics and Space Administration, 1979.

25. Konish HJ Jr and Cruse TA. Determination of Fracture Strength in Orthotropic Graphite-Epoxy Laminates. In: Composite Reliability, Special Technical Publication 580. American Society for Testing and Materials, 1975, pp. 490-503. 
26. Koiter WT. Note on the Stress Intensity Factors for Sheet Strips with Crack under Tensile Loads. Report 314, Laboratory of Engineering Mechanics, Delft University of Technology, Netherlands, 1965.

27. Brown WF and Srawley JE. Plane strain crack toughness testing of high strength metallic materials. Special technical publication no. 410, American Society for Testing and Materials, 1966.

28. Hoff NJ and Mautner SE. The Buckling of Sandwich-type Panels. J Aeronautical Sciences 1945; 12: 285-297.

29. Lekhnitskii SG. Anisotropic plates. Translated from the second Russian edition by Tsai SW and Cheron T. Philadelphia, USA: Gordon and Breach, 1968.

30. Tan SC. Finite-Width Correction Factors for Anisotropic Plate Containing a Central Opening. J Compos Mater 1988; 2: 1080-1097. 


\section{Reduction of Strength of GFRP Sandwich Panels in Naval Ships by Face Sheet Holes, Cracks and Impact Damage}

Figures

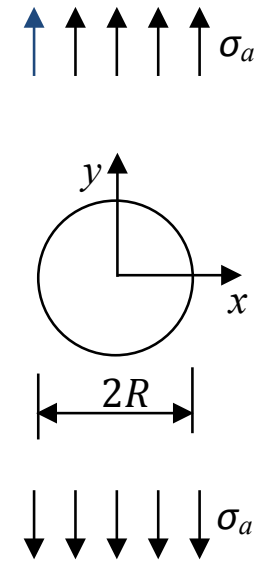

(a)
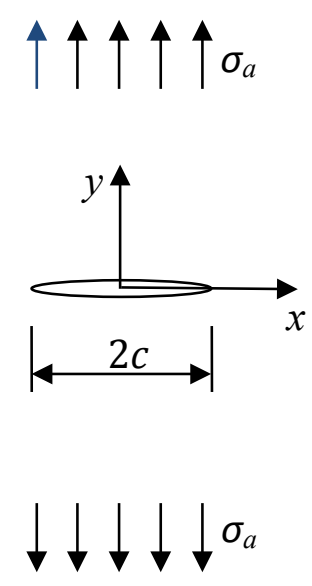

(b)

Figure 1. Tensile test specimens with (a) a circular hole of radius $R$ and (b) a transverse crack of length $2 c$.

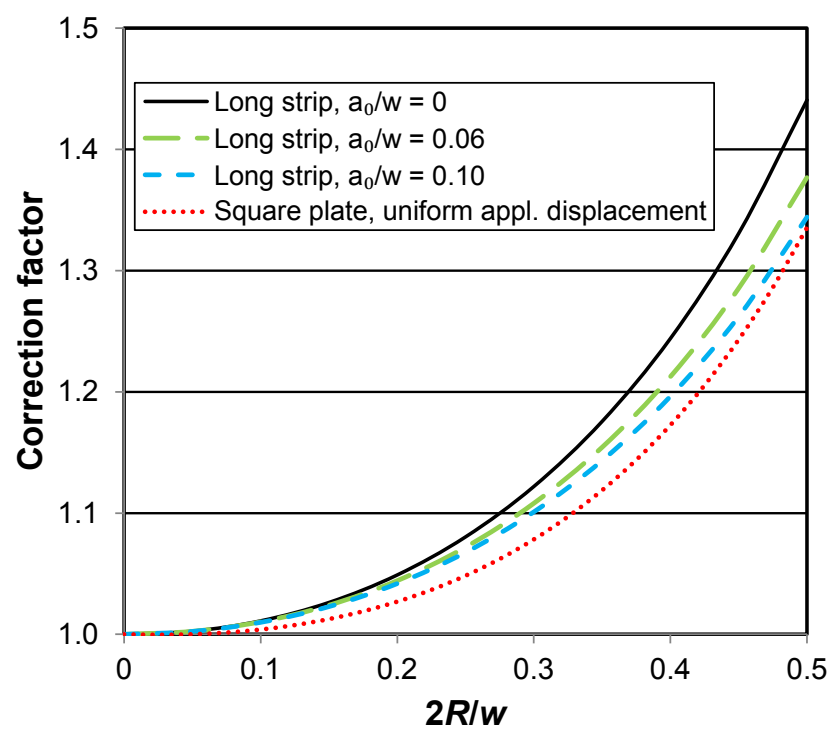

Figure 2. Finite width correction factors for long, rectangular strips under uniform tensile or compressive longitudinal applied stress and for square plates with uniform relative displacements applied at opposite edges. 


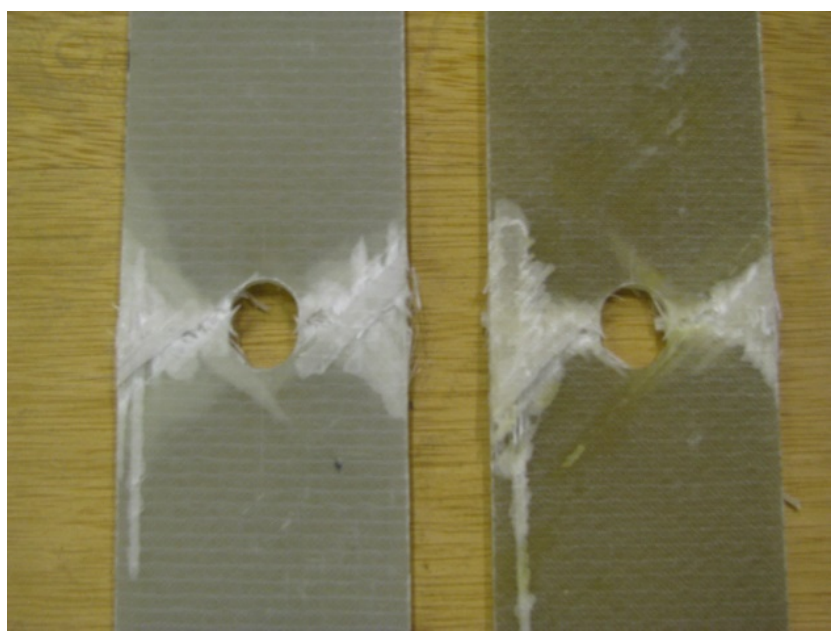

Figure 3. Failed laminates with $12 \mathrm{~mm}$ diameter holes, tested in tension - types LA4 (left) and LB4 (right).

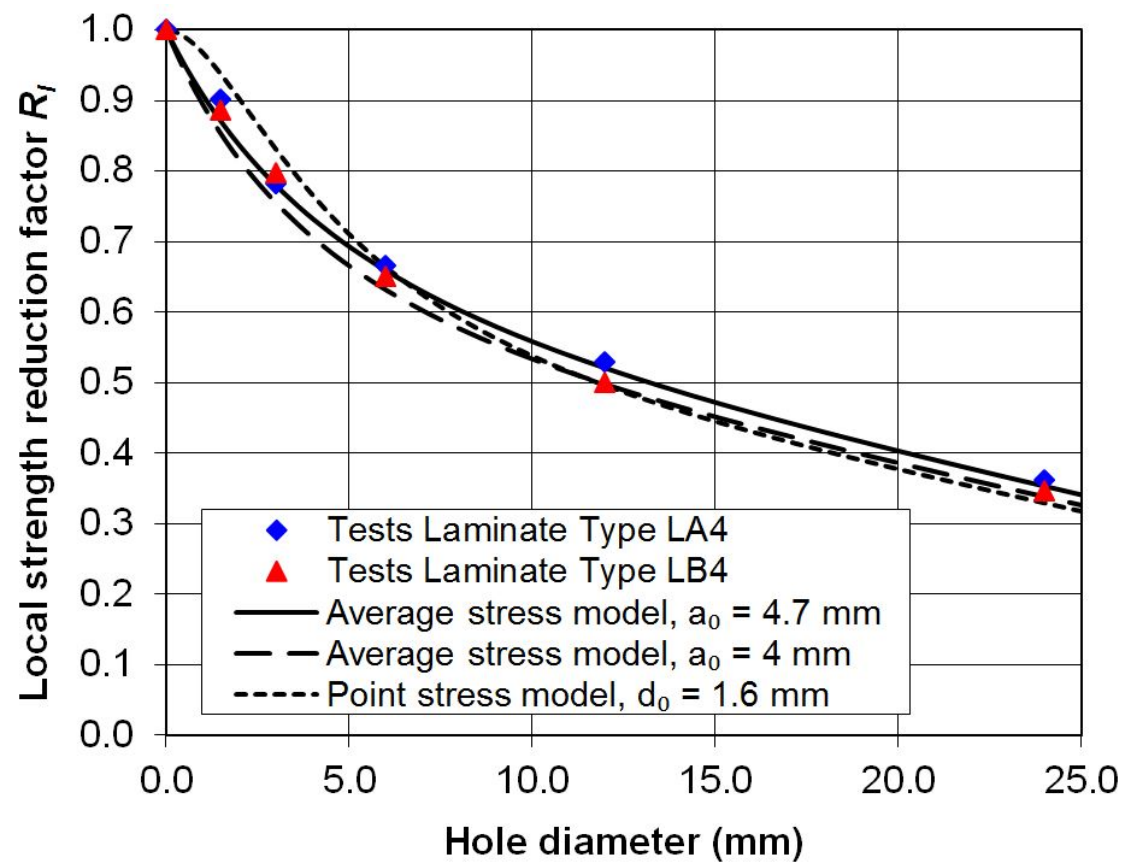

Figure 4. Local strength reduction factors for $50 \mathrm{~mm}$ wide laminates with holes under tensile loading - unadjusted test results compared with Whitney and Nuismer models adjusted to $50 \mathrm{~mm}$ specimen width. 


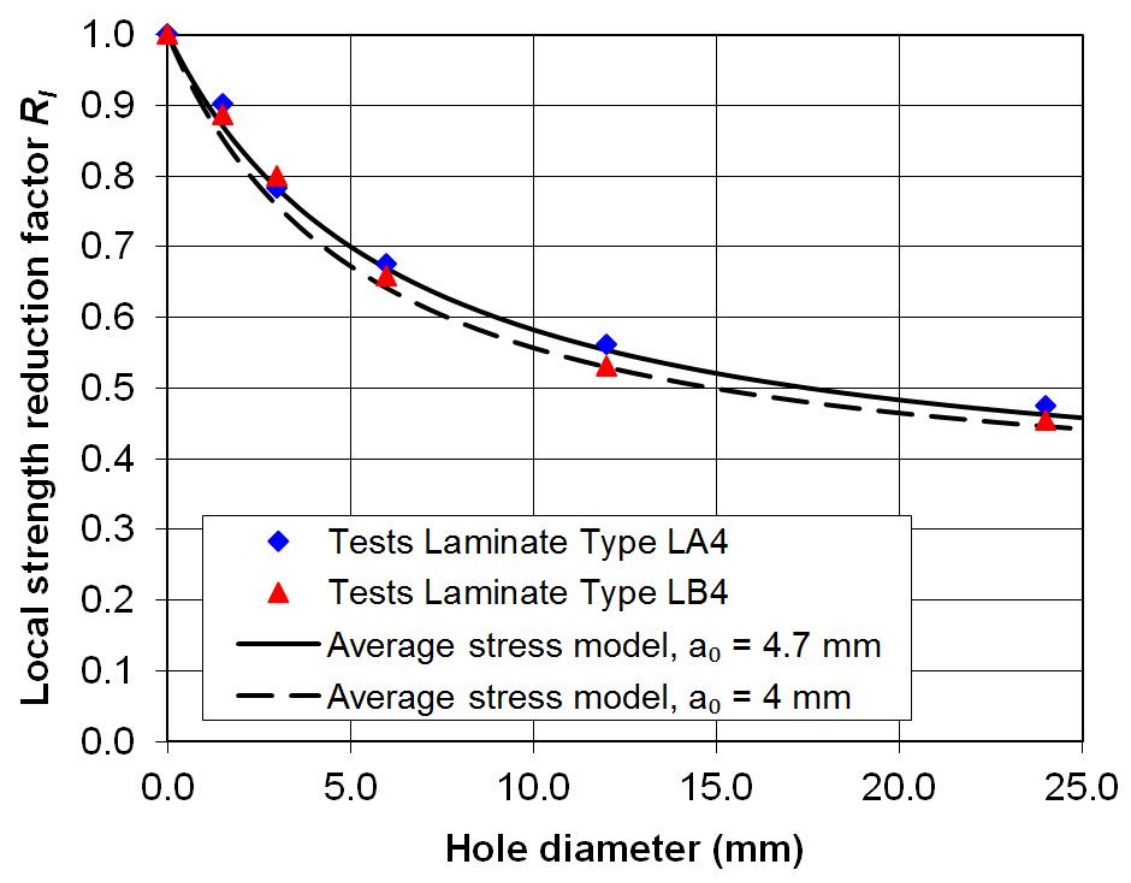

Figure 5. The same data as in Figure 4, adjusted to apply to laminates of infinite width. The point stress model curve is omitted.
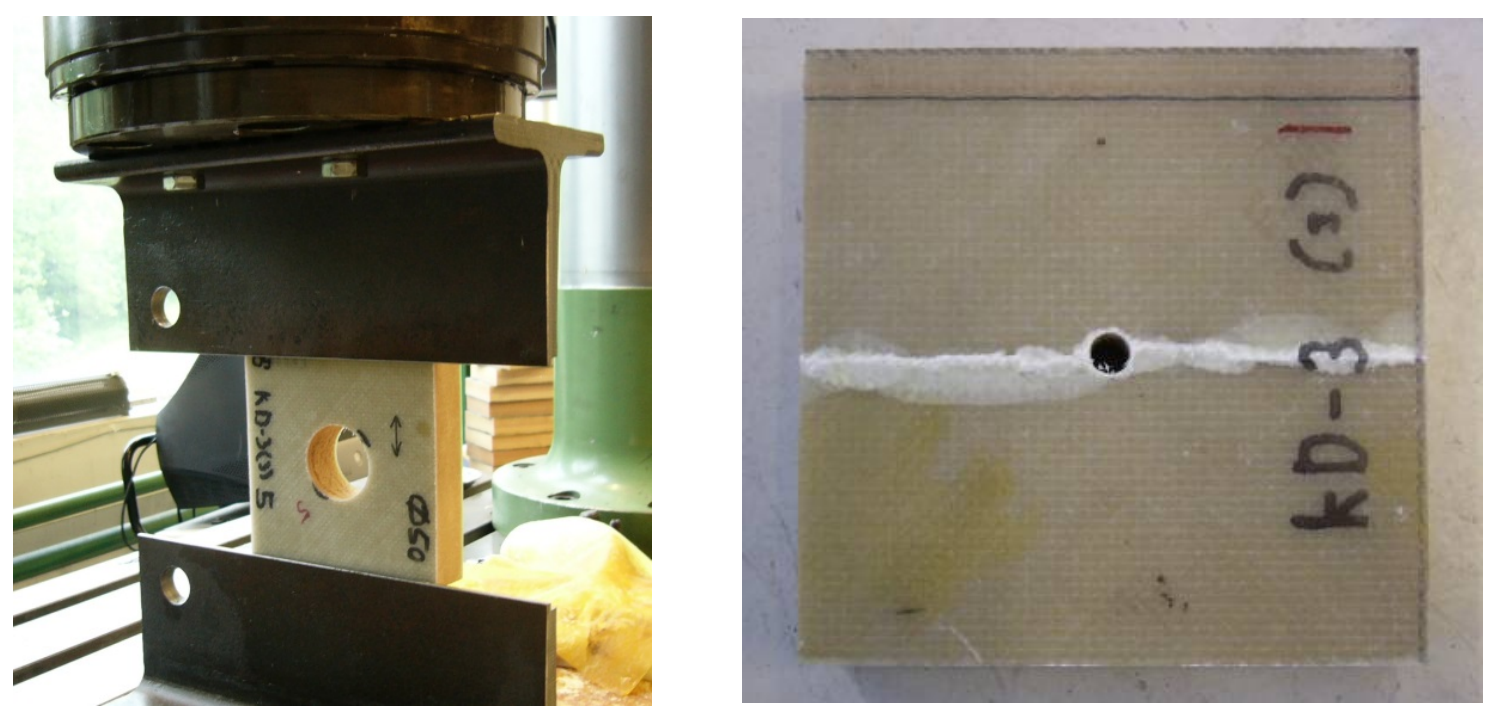

Figure 6. Left: Test arrangement for sandwich blocks with holes. Right: Sandwich block of Type SA3 with $10 \mathrm{~mm}$ diameter hole after testing in compression. 

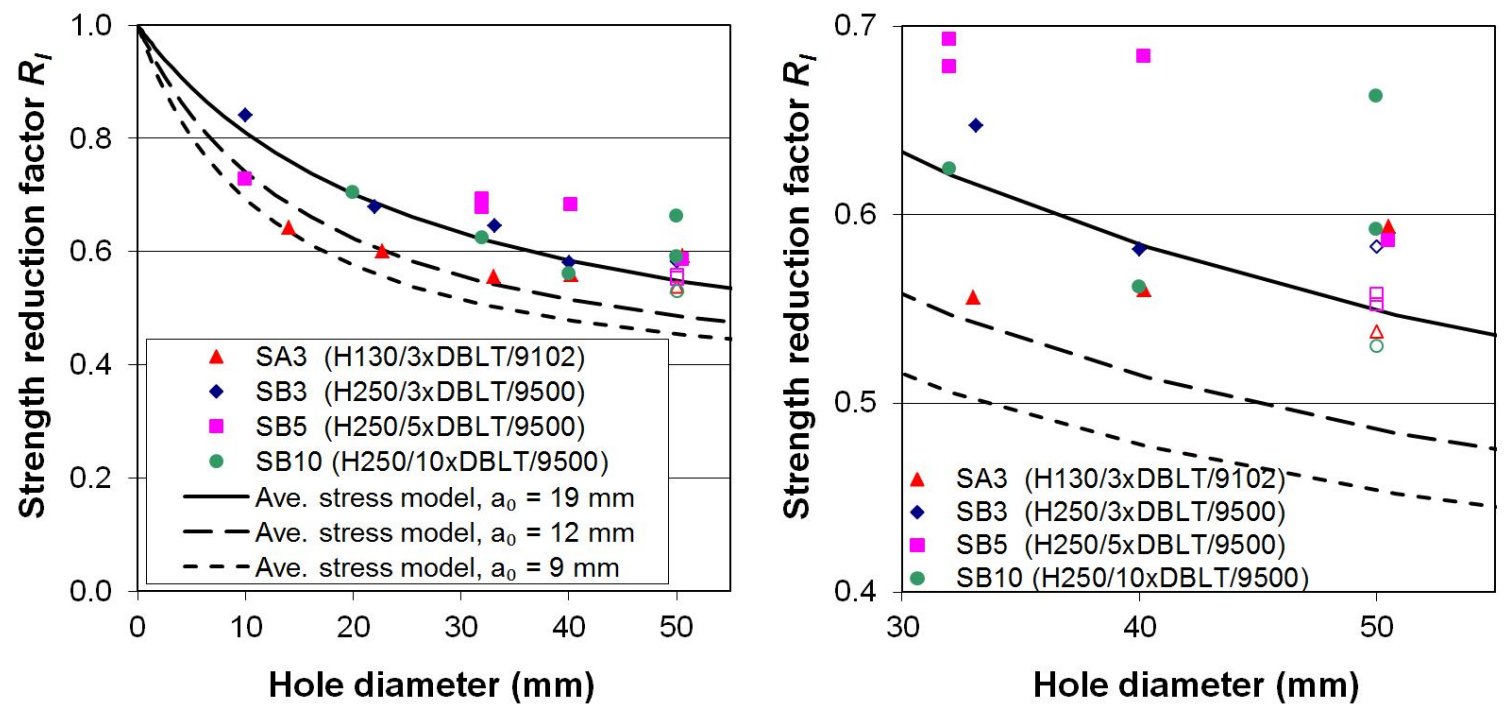

Figure 7. Left: Strength reduction factors $R_{l}$ of sandwich panels with machined circular holes, based on test results adjusted for finite panel width. Points with open symbols are for $300 \mathrm{~mm}$ x $300 \mathrm{~mm}$ panels, closed symbols are for $150 \mathrm{~mm}$ x $150 \mathrm{~mm}$ panels. The Whitney and Nuismer average stress criterion curves with $a_{0}=9 \mathrm{~mm}, 12 \mathrm{~mm}$ and $19 \mathrm{~mm}$ are also shown. Right: Enlarged view of part of the same plot.
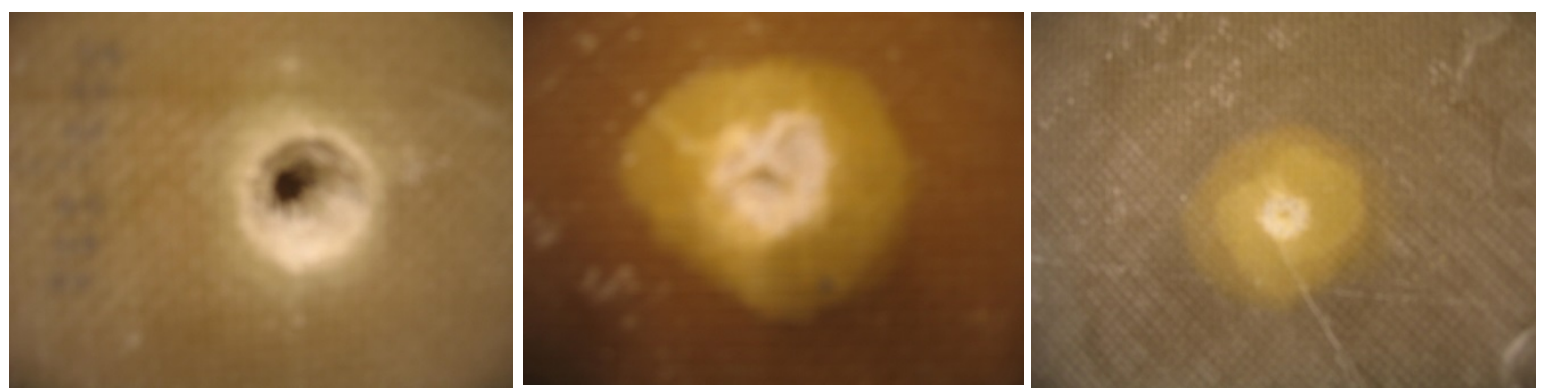

Figure 8. Impact damage on SA3, SB5 and SB10 sandwich panels before compression testing. 


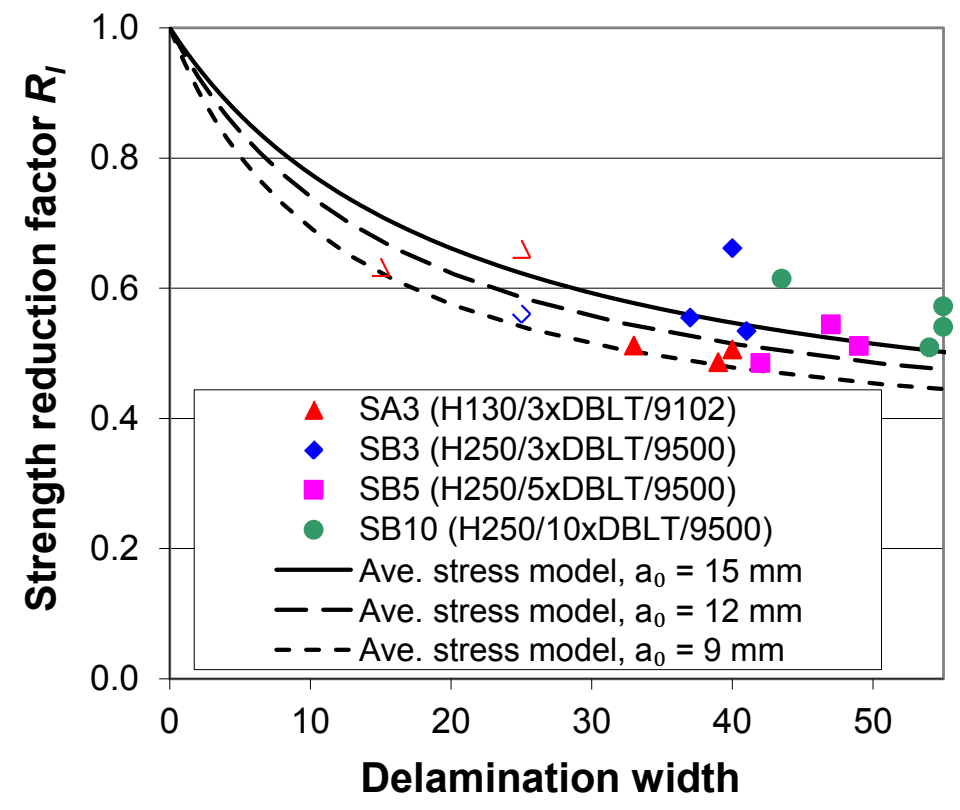

Figure 9. Local strength reduction factor $R_{l}$ for sandwich face sheets with blunt impact damage, based on test results adjusted for finite panel width. Points with open symbols represent cases where failure occurred at the loaded edge of the panel. The Whitney and Nuismer average stress criterion curves with $a_{0}=9 \mathrm{~mm}, 12 \mathrm{~mm}$ and $15 \mathrm{~mm}$ are also shown.
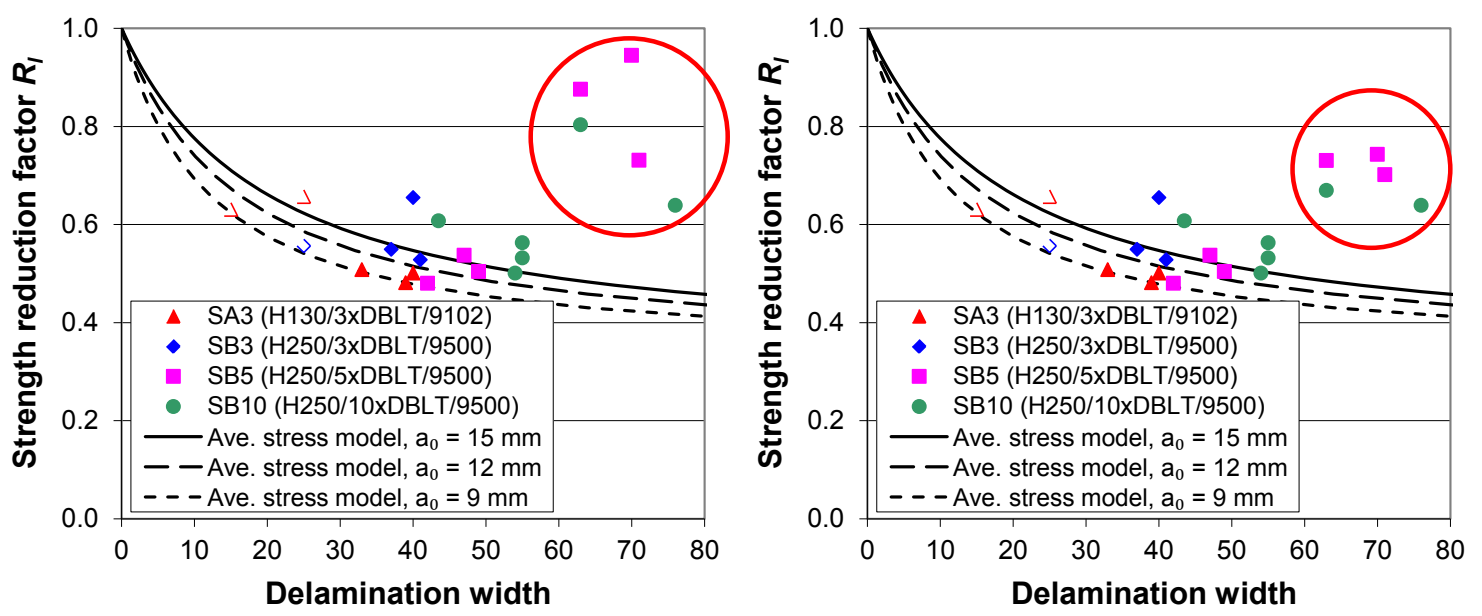

Figure 10. (Left) Local strength reduction factor $R_{l}$ for blunt impact damage, as presented in Figure 9. Points within the circle are for the additional tests with impactor B, giving delamination but no fibre breakage. (Right) The same plot modified by estimating the applied stress at failure by dividing the failure load by the gross cross-sectional area, i.e. not applying the finite width correction, for the cases within the circle. 

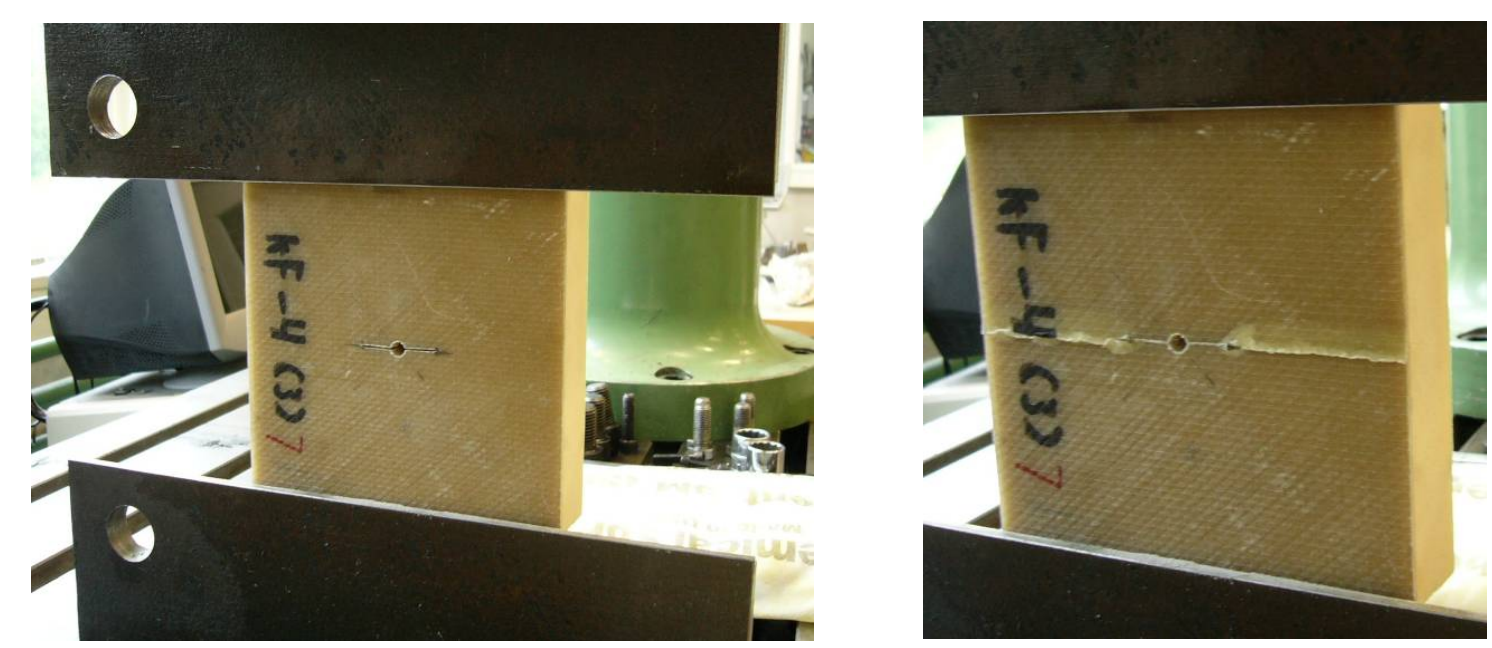

Figure 11. Sandwich specimen with machined slit/crack (left), mounted in test machine, and (right) same specimen after testing to failure.

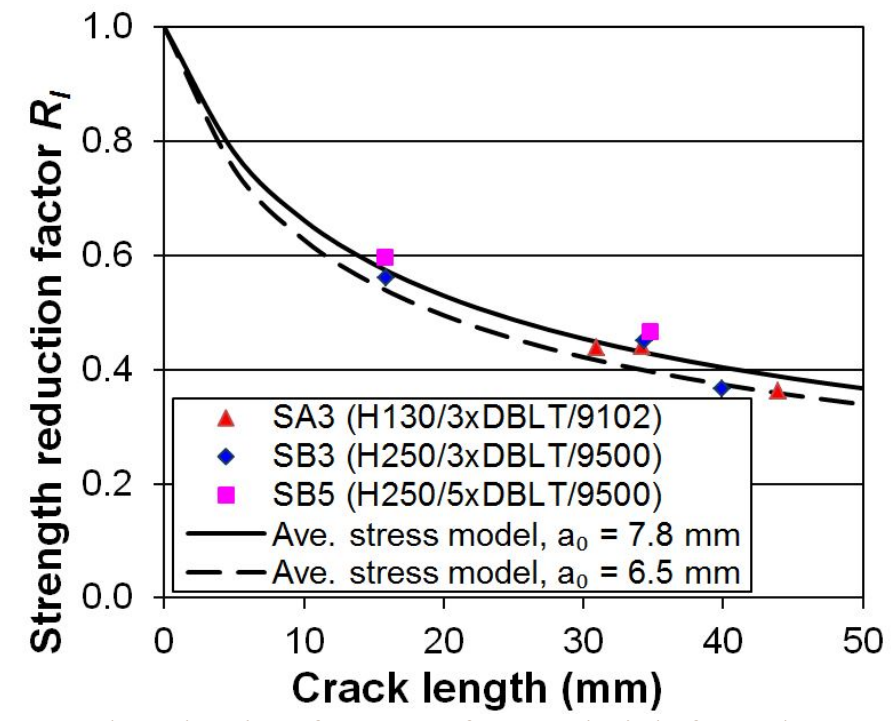

Figure 12. Local strength reduction factor $R_{l}$ for sandwich face sheets with machined slits/cracks transverse to loading direction, based on test results adjusted for finite panel width in accordance with the Koiter formula [26]. The Whitney and Nuismer average stress criterion curves for cracks assuming $a_{0}=7.8 \mathrm{~mm}$ and $6.5 \mathrm{~mm}$ are also shown. 


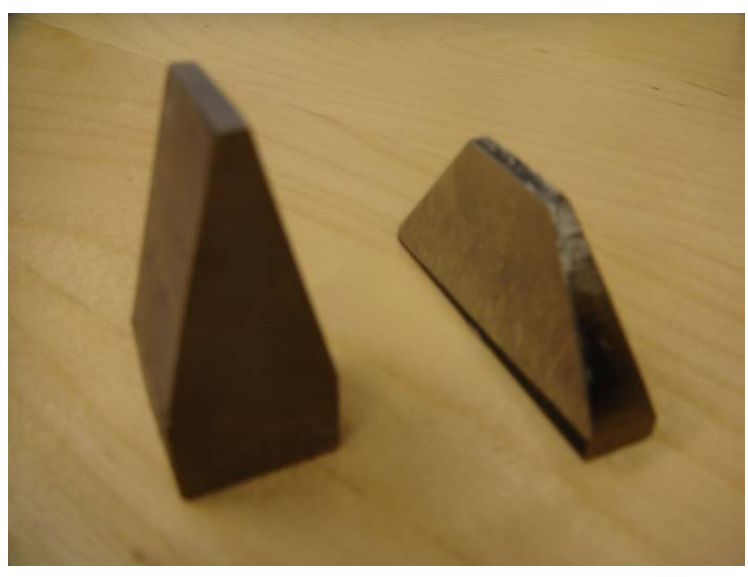

Figure 13: Sharp impactors.
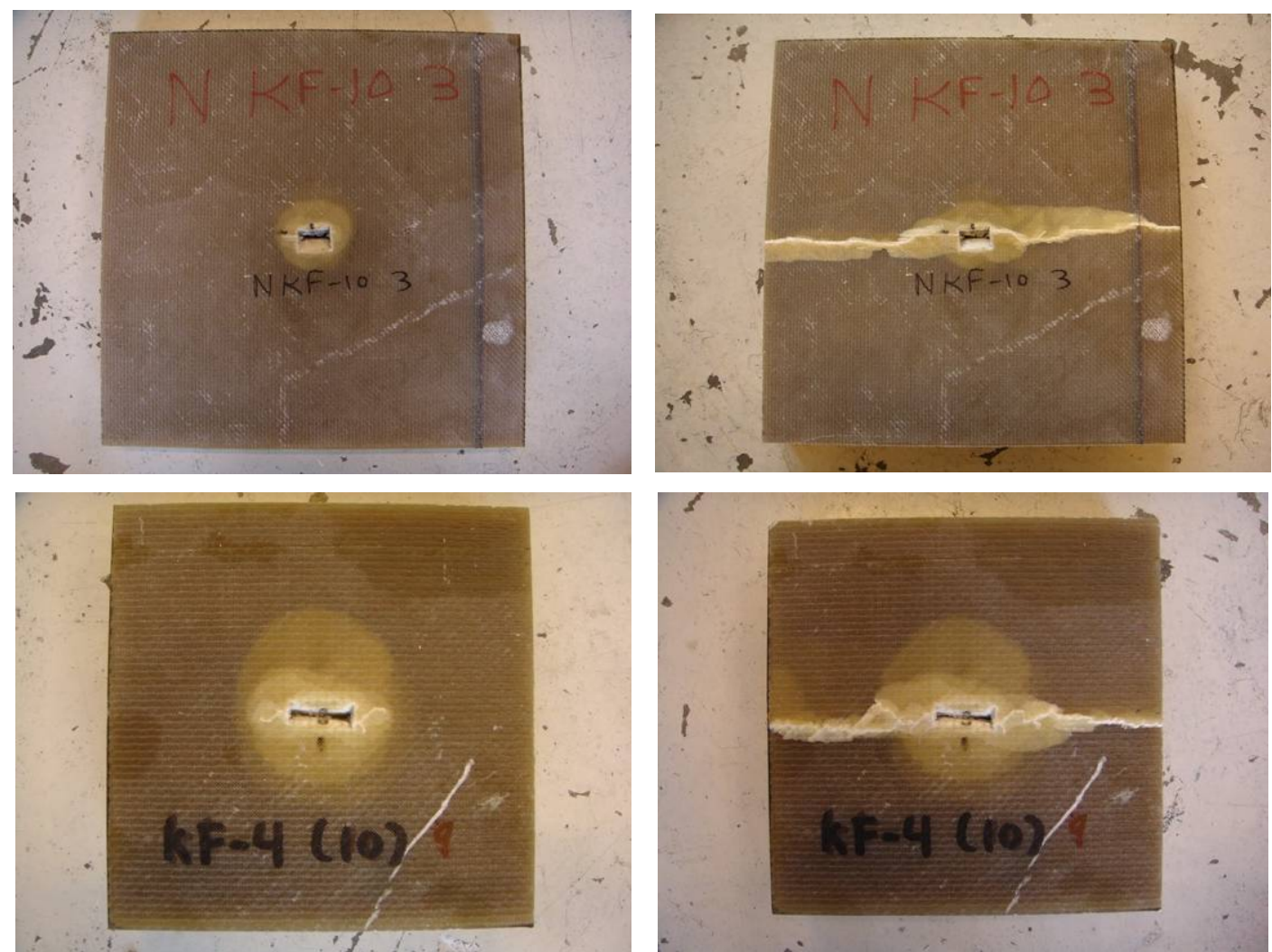

Figure 14. Some specimens with sharp impact damage before and after compression testing. 

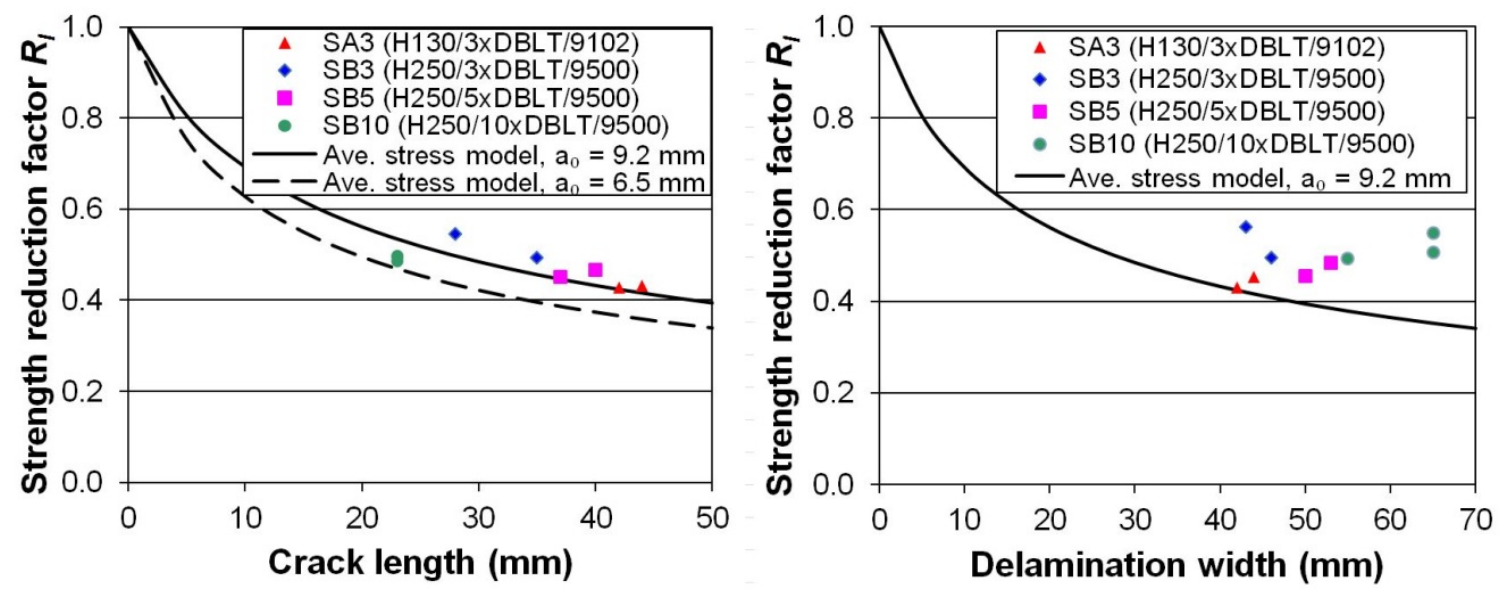

Figure 15. Local strength reduction factor $R_{l}$ for sandwich face sheets with sharp impact damage plotted against crack length due to impact (left) and delamination width (right).
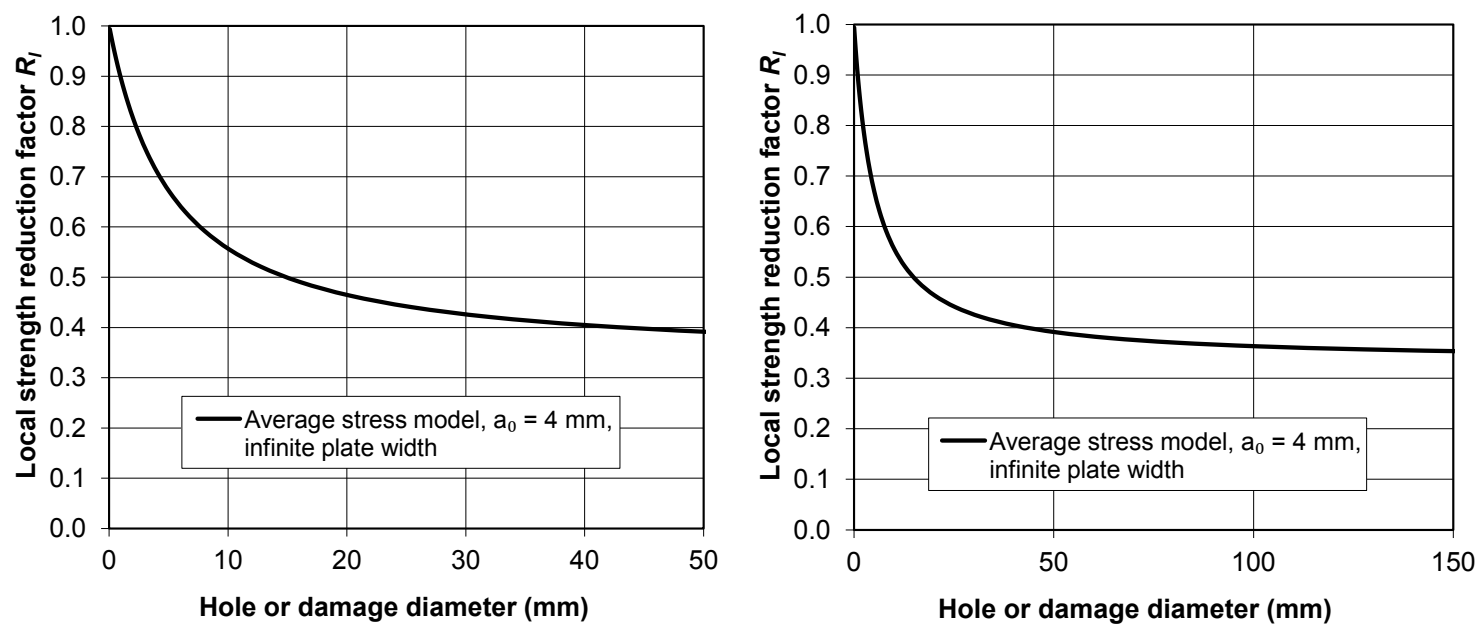

Figure 16. Proposed local strength reduction factor for sandwich face sheets with circular holes and blunt impact damage that are subjected to tensile loading. Plots with two different hole/damage diameter scales. 

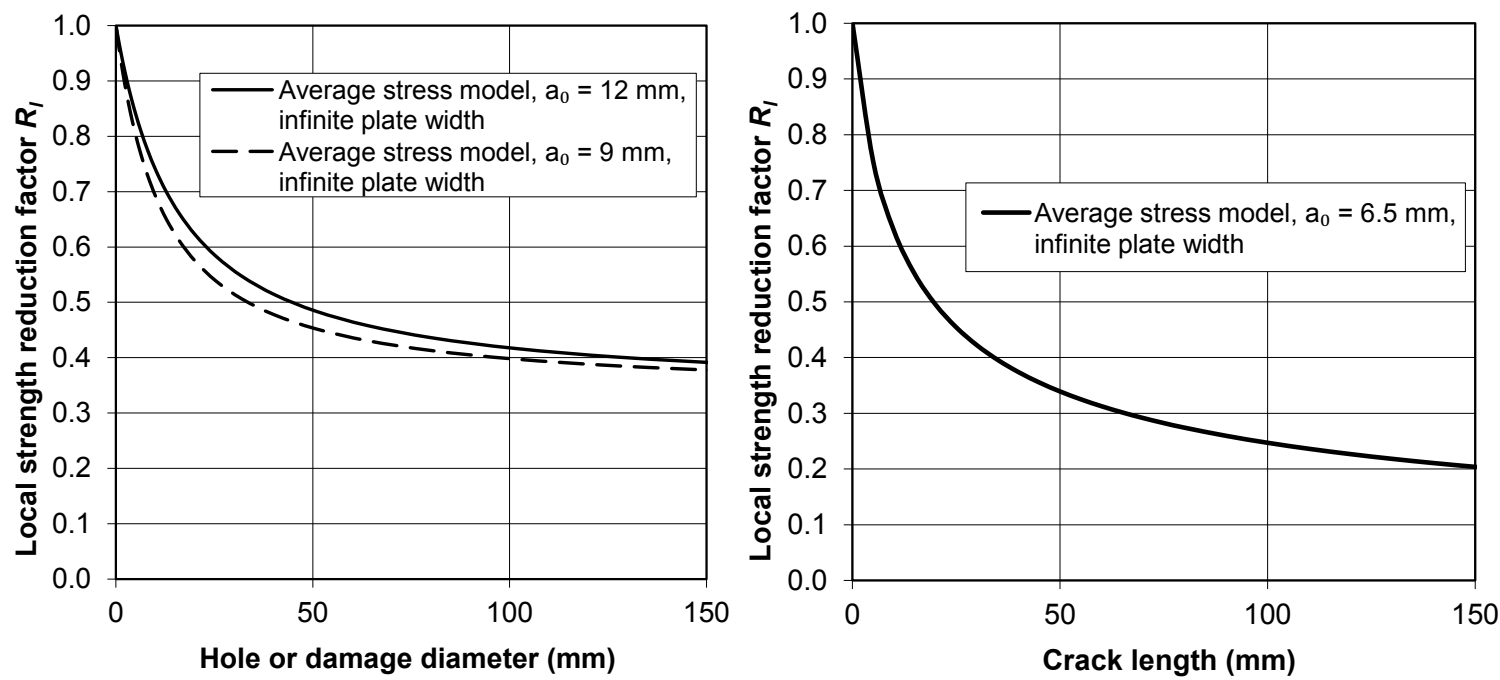

Figure 17. (Left) Proposed local strength reduction curves for sandwich face sheets with circular holes and blunt impacts when subjected to in-plane compression. Note that curves approach $R_{l}=0.33$. (Right) Corresponding curves for machined slits and sharp impacts. Note that this curve has no similar asymptote. 